\title{
COMPORTAMIENTOS RIESGOSOS ENTRE LOS JÓVENES: EL CASO DE LA ACTIVIDAD SEXUAL*
}

\author{
Francisca Dussaillant
}

En Chile nacen todos los años más de 35 mil hijos de madres adolescentes, lo que corresponde a alrededor del 15\% del total de niños nacidos. Muchos de esos nacimientos son frutos de embarazos no deseados que ocurren fuera de un matrimonio o convivencia estable. Este artículo se propone indagar acerca de la conducta de la población juvenil en Chile en materia de toma de riesgos, centrándose específicamente en las relaciones sexuales sin protección. Primero se presenta una revisión de la literatura sicológica respecto a las razones por las cuales los jóvenes tienden a tomar más riesgos que los adultos o los niños. A continuación se exponen resultados de investigaciones en sociología y economía, incluyendo análisis comparativos entre diferentes países. Finalmente, a la luz de resultados de estudios econométricos de la conducta

Francisca Dussaillant. Ingeniera Civil Industrial y doctora en Economía de la Universidad Católica de Chile. Master of Arts en Educación de University of North Carolina-Chapel Hill. Profesora e investigadora de la Facultad de Gobierno, Universidad del Desarrollo.

* Realicé este trabajo durante mi permanencia como investigadora del Centro de Estudios Públicos. Agradezco los comentarios de Harald Beyer, Arturo Fontaine, Tomás Rau, Sergio Urzúa y Eduardo Valenzuela. Por supuesto, cualquier error u omisión es de mi exclusiva responsabilidad. 
sexual de los adolescentes y jóvenes chilenos, se propone una caracterización de la situación en nuestro país y se sugieren cursos de acción en materia de política pública.

Palabras clave: conductas riesgosas; embarazo adolescente; sexualidad juvenil.

Recibido: marzo 2010.

\section{Introducción}

$\mathrm{P}_{\mathrm{o}}$ les de los jóvenes, especialmente poco se ha escrito desde una disciplina como la economía. Sin embargo, el tema a tratar es muy relevante: en Chile nacen todos los años más de 35 mil hijos de madres adolescentes (menores de 20 años de edad), lo que corresponde a alrededor del $15 \%$ del total de niños nacidos ${ }^{1}$. Muchos de estos hijos de madres adolescentes son frutos de embarazos no deseados que ocurren fuera de un matrimonio o convivencia estable. Es común que los padres de estos niños estén ausentes o poco a poco se vayan desvinculando de la madre y su hijo. Estas madres en ocasiones ven en la maternidad una oportunidad para realizarse y crecer en una relación de mutuo cariño con el niño. Pero en otras ocasiones ven truncados sus proyectos de trabajo o estudios y ven muy dificultados sus caminos hacia una vida adulta estable y plena. De hecho, alguna de estas jóvenes decide abortar, de manera ilegal, al hijo recién concebido.

La Sexta encuesta del Instituto Nacional de la Juventud, realizada en 2009, indica que alrededor del 30\% de las jóvenes de entre 15 y 29 años ha tenido un embarazo no planificado. La mayor parte de estos embarazos (60,4\%) ocurre en jóvenes menores de 20 años y el 6,7\% de quienes han tenido embarazos no planificados reporta haberse realizado un aborto ${ }^{2}$. Los jóvenes chilenos se inician en la vida sexual relativamente temprano (a los 16,4 años los hombres y 17,1 las muje-

${ }^{1}$ Específicamente, en 2009 nacieron 53.838 hijos de mujeres menores de 21 años (20,3\% del total de nacimientos del año). Si desglosamos por edad nos encontramos con que de esos niños 25386 nacieron cuando sus madres tenían entre 19 y 20 años, 24.471 cuando éstas tenían entre 16 y 18 años y 3.981 cuando tenían 15 años o menos (Registro Civil y de Identificación).

${ }^{2}$ Cifra posiblemente subestimada, ya que la encuesta del Instituto Nacional de la Juventud se realiza cara a cara. 
res) y no toman las precauciones adecuadas para evitar las consecuencias no previstas y no deseadas de un encuentro sexual, es decir, el embarazo y las enfermedades de transmisión sexual (ETS). De hecho, casi la mitad (el 46,8\%) de los jóvenes de 15 a 29 años menciona no haberse cuidado en su primera relación sexual, cifra que por lo menos duplica la de países desarrollados como Suecia, Francia, Inglaterra y Estados Unidos. Por otro lado, cerca de la cuarta parte de estos jóvenes reporta en 2009 no haberse cuidado en su último encuentro sexual, cifra nuevamente muy alta para los estándares de países desarrollados (ver, por ejemplo, Darroch et al., 2001). Todo indica, entonces, que en nuestro país hay un problema de magnitud.

Las relaciones sexuales desprotegidas son un ejemplo de conducta riesgosa cuyas consecuencias pueden ser negativas, pero no son las únicas conductas de riesgo que atraen a los jóvenes: la conducción de vehículos a exceso de velocidad, el alcoholismo y las drogas, los actos criminales e incluso los intentos de suicidio son mucho más frecuentes en la población adolescente que en la población general. Estos comportamientos de los jóvenes han sido motivo de extensas discusiones en la psicología, desde distintas ópticas. Por su parte, la economía y la sociología no se han quedado atrás en la búsqueda de una explicación para estas conductas y de políticas para prevenirlas. Diversos trabajos han aislado los factores que se relacionan más fuertemente con la conducta riesgosa del joven y han tratado de dilucidar hasta qué punto estas conductas son modificables mediante estrategias que busquen cambiar tanto los costos reales de las acciones del joven como su percepción y conocimiento de estos $\operatorname{costos}^{3}$. Estas estrategias, sin embargo, no son suficientes para eliminar el problema, por lo que también hay aproximaciones — que describiremos más adelantedirigida a encarar la proclividad de los jóvenes a dejarse llevar por sus impulsos e impresiones erradas de la realidad, así como a sentirse presionados por sus parejas y pares.

Comenzando con un recuento de la literatura sobre conductas de riesgo en general en la adolescencia, este trabajo se propone indagar los

\footnotetext{
${ }^{3}$ Estrategias para cambiar los costos reales incluyen, por ejemplo, programas que aumenten o disminuyan la protección estatal a madres adolescentes embarazadas. Las estrategias para cambiar la "percepción" de estos costos son en general aquellas que buscan entregar información a los jóvenes que hasta el momento no era conocida (por ejemplo, enseñarles la forma en que se transmite el sida y explicarles las consecuencias de portar esa enfermedad durante el resto de su vida en caso de contagiarse).
} 
factores que inciden en las conductas sexuales de los jóvenes chilenos. En particular, se busca explorar mediante estudios econométricos los determinantes de la decisión de iniciarse sexualmente y de tomar o no precauciones al momento de tener una relación sexual. Analizaremos en detalle los datos de la Quinta Encuesta Nacional de la Juventud (2006), complementados con otras encuestas realizadas ese mismo año (Casen y encuesta de drogas en población general de Conace). Intentaremos verificar si los jóvenes chilenos se parecen a los jóvenes que han sido estudiados en otros países y haremos un esfuerzo por determinar, al menos en parte, cuáles son los factores más relevantes que explican su conducta sexual. A la luz de los resultados obtenidos, finalmente sugerimos algunas medidas que podrían ayudar a los jóvenes a actuar de manera responsable y así evitar consecuencias inesperadas que, por lo menos en el caso del embarazo, tienen la particularidad de afectar negativamente no sólo a los "tomadores de riesgos" (los jóvenes) sino también a terceros (los hijos).

\section{LOS JÓVENES Y EL RIESGO: APORTES TEÓRICOS, EMPÍRICOS Y DE POLÍTICA PÚBLICA DESDE LA PSICOLOGÍA}

Como se dijo en la Introducción, el tema de la toma de riesgos, al parecer excesivos durante la adolescencia, se ha estudiado bastante a nivel internacional. Los jóvenes tienden a tener algunos comportamientos que parecen muy riesgosos, especialmente si los comparamos con el comportamiento de los adultos. De hecho, la probabilidad de involucrarse en gran parte de las conductas riesgosas disminuye significativamente con la edad (Reyna y Farley, 2006).

El crimen, el consumo de drogas, el alcoholismo, la conducción imprudente de vehículos, los encuentros sexuales casuales y sin protección son algunos ejemplos de conductas que comienzan en la adolescencia y tienen una prevalencia bastante inferior entre individuos adultos. Algunas veces las conductas riesgosas de los jóvenes les pueden costar la vida o perjudicar de manera importante sus proyectos vitales.

La literatura psicológica ha estudiado en profundidad este fenómeno en un intento por explicar el porqué de estas conductas. A continuación se presenta un breve recuento de esta literatura, basado 
en publicaciones recientes, algunas de las cuales son recuentos (también parciales, probablemente) de la literatura pasada. Es importante clarificar que la exposición que incluimos a continuación no pretende cubrir la totalidad del conocimiento en esta amplia área, y que necesariamente presenta un punto de vista parcial del que se excluyen visiones provenientes de otras aproximaciones que muchas veces son un importante complemento (o en ocasiones podrían estar en contradicción) de las aproximaciones aquí presentadas.

\section{El estereotipo equivocado}

En su recuento de la literatura sobre toma de riesgos en la adolescencia, Reyna y Farley (2006) sostienen que la investigación psicológica no respaldaría la visión estereotipada de los adolescentes como individuos irracionales que se creen invulnerables y que no conocen o no están atentos ni les preocupan los potenciales daños que pueden sufrir a causa de las conductas riesgosas. De hecho, los autores argumentan que las habilidades de razonamiento lógico de un joven de 15 años son comparables con las de un adulto. Los adolescentes, al parecer, no tendrían capacidades inferiores a las de los adultos en su percepción de los riesgos y en su cálculo de cuán vulnerables son a estos riesgos. Además, agregan, cuando aumenta la notoriedad de los riesgos asociados a alguna decisión, el comportamiento adolescente cambia de la misma manera que el de un adulto. Al parecer, en su mayoría los estudios experimentales en el área no encontrarían demasiadas diferencias de edad en las evaluaciones que los individuos hacen de las consecuencias asociadas a diferentes comportamientos riesgosos, y tampoco encontrarían variación etaria en las maneras en que los costos y beneficios relativos de las actividades riesgosas son evaluados (Steinberg, 2007, 2008). Aparentemente, es cierto que los jóvenes presentan un sesgo optimista, es decir perciben sus propios riesgos conductuales como inferiores a los de sus pares con conductas comparables. Sin embargo, este sesgo optimista también estaría presente, con una intensidad y prevalencia similares, en los adultos. Finchhoff (2008) está de acuerdo en que los jóvenes no se sienten invulnerables. El autor ha buscado cuantificar las discordancias entre la percepción de riesgo de los jóvenes y su riesgo real. Sus resultados muestran que los jóvenes, en algunos riesgos específicos, incluso "sobreestimarían” su 
vulnerabilidad (por ejemplo, sus creencias respecto de la probabilidad de ser arrestados o de morir en el corto plazo superan la realidad). Por otro lado su evidencia muestra que en la percepción de vulnerabilidad ante otros riesgos específicos (como la posibilidad de abandonar la escuela o embarazarse en el caso de las mujeres) los jóvenes los subestiman. De hecho, su evidencia para adolescentes de 15 y 16 años muestra que en promedio las mujeres creen que su probabilidad de embarazo en el próximo año es de $8,9 \%$ y que su probabilidad de embarazo antes de cumplir 20 años es de 9,4\%. Sin embargo las probabilidades observadas en este caso son mucho mayores (20,1 y $25,7 \%$, respectivamente). Es interesante notar, sin embargo, que esta subestimación de la probabilidad de dejar a alguien embarazada no se observa en los hombres: de hecho ellos tienden a sobreestimar este tipo de riesgos ${ }^{4}$.

La aseveración de que los jóvenes y los adultos no se diferenciarían demasiado en su percepción de los riesgos asociados a diversas conductas se contrapone con la observación de que los jóvenes de hecho toman más riesgos que los adultos. ¿Es posible dar una explicación a ese fenómeno? Al parecer el problema no estaría tanto en lo que los adolescentes "saben" o en sus evaluaciones subjetivas, sino en lo que objetivamente "hacen”. En muchas ocasiones ellos contarían con la información relevante sobre los riesgos asociados a determinadas conductas, y por tanto sus conductas riesgosas no se deberían a la falta de información. La literatura analizada apunta a que la explicación de todo esto radicaría en el hecho de que la toma de riesgos en la vida real no es producto sólo del pensamiento lógico sino también de factores psicosociales. A diferencia de las habilidades lógicas, que estarían desarrolladas en plenitud en jóvenes de 15 años, las habilidades psicosociales (como el control de los impulsos, regulación de las emociones, capacidad de demorar las gratificaciones y resistencia a la influencia de los pares), que mejoran la calidad del proceso de toma de decisiones y por tanto actúan como moderadores en la toma de riesgos, al parecer tardan mucho más en madurar. Por lo tanto, la conclusión de que los adolescentes son tan competentes como los adultos en la toma de

\footnotetext{
${ }^{4}$ En promedio los hombres creen que su probabilidad de dejar embarazada a alguien en el próximo año es de 9,4\% y su probabilidad dejar embarazada a alguien antes de cumplir 20 es de $19,1 \%$. Sin embargo las probabilidades observadas son menores (7,9 y 13,4\% respectivamente).
} 
decisiones sólo sería cierta bajo condiciones en las que la importancia de los factores psicosociales es minimizada (Steinberg, 2007, 2008).

La investigación en neurociencia ha tomado relevancia en el análisis de conductas riesgosas adolescentes. Esta línea de investigación es un aporte novedoso para entender los mecanismos sociales, emocionales y cognitivos del desarrollo humano. Según esta línea (y también según otras aproximaciones complementarias de la psicología), la piedra angular del desarrollo cognitivo estaría en la adquisición de la capacidad para suprimir pensamientos y acciones inapropiados en favor de aquellos que sirven a nuestros objetivos, aun en presencia de grandes estímulos para la acción inapropiada. En otras palabras, la clave estaría en el control de la impulsividad o la capacidad de retrasar la gratificación.

Steinberg (2007) afirma que al parecer existirían dos redes a nivel cerebral ${ }^{5}$ que modularían el comportamiento: una de ellas, la llamada "red socioemocional", sería muy sensible a estímulos sociales y emocionales y estaría vinculada de manera particularmente importante al procesamiento de las recompensas o gratificaciones. Esta red se alteraría profundamente al inicio de la adolescencia, fruto de los cambios hormonales ocurridos durante la pubertad. La segunda red, denotada por el autor como "red de control cognitivo", se encargaría de funciones ejecutivas como la planificación, la previsión y la autorregulación, entre otras. Esta red maduraría gradualmente durante el curso de la adolescencia y la adultez joven ${ }^{6}$ y su proceso de maduración sería independiente de la pubertad. En muchos aspectos, la toma de riesgos sería entonces el producto de la competencia entre la "red socioemocional" y "la red de control cognitivo".

Según la explicación de Steinberg (2007), la adolescencia sería un momento en el cual la "red socioemocional" abruptamente ganaría asertividad, mientras que la "red de control cognitivo" ganaría fuerza sólo de manera gradual, a lo largo de un proceso mucho más extenso en el tiempo. La red socioemocional, sin embargo, no se encuentra en estado de alta activación en todo momento durante la adolescencia. De

\footnotetext{
${ }^{5}$ Estas redes han sido identificadas en lugares específicos del cerebro. Sin embargo no es nuestro objetivo aquí entrar en ese tipo de detalles. El lector interesado puede recurrir a las fuentes originales: Steinberg $(2007,2008)$, Casey et al. (2008).

${ }^{6}$ En general adolescencia se considera un período que terminaría alrededor de los 20 años, y la adultez joven sería el período de entre los 20 y 24 años, aproximadamente.
} 
hecho, cuando la red no está altamente activada (por ejemplo cuando el joven está solo, o en un estado de baja excitación), la red de control cognitivo sería lo suficientemente fuerte como para imponer un control regulatorio sobre potenciales comportamientos riesgosos, incluso en la adolescencia más temprana. Sin embargo, cuando el joven está acompañado de pares o en condiciones de alta excitación, la red socioemocional se activaría para disminuir o anular los efectos regulatorios de la red de control cognitivo, aún no suficientemente madura. En un momento de exaltación o entusiasmo, en presencia de pares, o en situaciones poco familiares donde el tradeoff entre riesgos y beneficios desfavorece la acción, pero algún grado de inhibición conductual es requerido para llegar a buen puerto, los adolescentes tendrían más dificultades para razonar que los adultos, ya que la madurez cerebral de los primeros sería incompleta. Al parecer, según aumenta la edad, la red de control cognitivo iría ganando madurez y por lo tanto serían cada vez menos las situaciones en que el individuo no estaría en condiciones de modular sus inclinaciones hacia la toma de riesgos (Steinberg, 2007, 2008; Reyna y Farley, 2006).

\section{El efecto de los pares}

Una de las características principales de las conductas riesgosas en la adolescencia es que éstas ocurren con gran frecuencia en contextos grupales. En la población adulta la frecuencia en que las conductas riesgosas se dan en grupo es bastante menor. De hecho, el grado en que los pares de un adolescente consumen alcohol o drogas ilícitas sería uno de los predictores más fuertes del uso de estas sustancias por parte de éste. La investigación sobre accidentes automovilísticos indicaría que la presencia de pares en un automóvil conducido por un adolescente incrementaría significativamente el riesgo. Además, aparentemente los adolescentes tienen mayor probabilidad de ser activos sexualmente cuando sus pares lo son, o cuando creen (sin importar si la creencia es verdadera o falsa) que éstos ya han comenzado su actividad sexual. Por otro lado, al parecer, cuando los adolescentes cometen crímenes es mucho más común que lo hagan en grupo que cuando lo hacen los adultos (Steinberg, 2008) ${ }^{7}$.

${ }^{7}$ En Steinberg (2008) se encuentran las citas de la investigación que muestra la evidencia recién mencionada. 
Según Steinberg (2007), existiría evidencia de que la adolescencia es una época que, respecto de la adultez, se caracterizaría por una mayor notoriedad en las recompensas o gratificaciones (reward salience). Podría especularse por tanto que cuando los adolescentes se enfrentan a decisiones riesgosas con recompensas o gratificaciones potenciales y también con costos potenciales, serían más sensibles que los adultos a variaciones en las recompensas, pero igualmente sensibles (o quizá menos sensibles) que éstos a las variaciones en los costos. Una de las razones por las cuales las conductas riesgosas adolescentes ocurren en grupos puede ser simplemente el hecho de que estos jóvenes pasan más tiempo con sus amigos. Sin embargo, una explicación alternativa, la preferida por Steinberg (2008), es que la presencia de pares activaría en los jóvenes el mismo circuito neuronal implicado en el procesamiento de recompensas, y que esto impulsaría a los jóvenes a buscar nuevas sensaciones. En otras palabras, a nivel cerebral existe un circuito que se activa frente a recompensas o gratificaciones. Al parecer este mismo circuito se activaría en los jóvenes (y no en individuos de otras edades) cuando están en presencia de pares.

La evidencia citada en Steinberg (2007) muestra que la vulnerabilidad de los jóvenes a la presión de sus pares aumentaría entre la preadolescencia y la adolescencia media y decaería gradualmente a continuación. Aparentemente, la presencia de pares incrementaría la toma de riesgos de manera sustantiva en los menores de 20, de manera moderada en los jóvenes en edad universitaria, y no la afectaría en lo absoluto en la adultez. Comprender que, como consecuencia de los procesos ocurridos en la pubertad, la atención a los estímulos sociales se ve muy incrementada durante la adolescencia sería clave para entender las conductas riesgosas de los adolescentes. Así, la presencia de pares sería un elemento clave en la estimulación de este tipo de conductas en los jóvenes (Steinberg 2008) ${ }^{8}$.

\section{Teorías psicológicas y política pública}

El modelo recién presentado no se contrapone a la idea de jóvenes capaces de ejercer algún grado de racionalidad, por lo menos en

${ }^{8}$ La observación de que la presencia de los pares influiría en la toma de decisiones de los jóvenes no es novedosa ni particular de Steinberg. Lo que hace el autor es estudiar este efecto desde un punto de vista neurológico y avanzar en el proceso de confirmar la base neurológica en las observaciones que venían haciéndose hace ya tiempo en el área. 
determinadas circunstancias. Sin embargo la evidencia apuntaría a que los modelos puramente racionales no son lo suficientemente potentes como para explicar las conductas riesgosas de los jóvenes. Al parecer son muchos los académicos que están de acuerdo con que la racionalidad pura no es capaz de explicar en su totalidad algunas conductas que son bastante comunes en los jóvenes, como tener sexo sin protección cuando no se desea un embarazo, o conducir en estado de ebriedad ${ }^{9}$. Por ello, han surgido algunos modelos de toma de decisión, llamados "modelos de procesos duales", que identifican dos procesos divergentes en la toma de riesgos: una ruta razonada o deliberativa (en que se consideran las opciones, se evalúan las consecuencias y luego se toma la decisión; en otras palabras, la ruta racional, donde el individuo decide luego de contrapesar costos y beneficios) y una ruta reactiva o intuitiva. La vía reactiva o intuitiva sería rápida y asociativa, en contraposición a la vía deliberativa, que sería lenta y analítica. Existen diversos modelos en la línea dual recién descrita. Aunque difieren en algunas conceptualizaciones básicas, en general tienen bastantes similitudes. Un ejemplo de modelo dual es el que se construye en la línea de la teoría del "prototipo/disposición” (prototype/willingness theory). Este modelo enfatiza una vía reactiva que supondría reacciones no deliberativas frente a ideas esenciales o prototípicas de la acción a decidir. Por ejemplo, un joven cuyo prototipo mental del fumador sea como el del "hombre Marlboro", al que las mujeres se le acercan por montones, tendría más probabilidades de fumar en un momento dado que otro que tuviese la imagen prototípica asociada a una traqueotomía. Según la teoría, lo importante en los prototipos mentales, más que el detalle de éstos, sería su grado de positividad o negatividad. La teoría predice que al tener un joven un prototipo mental positivo hacia una conducta riesgosa, éste tendría una mayor disposición (willingness) hacia esa conducta, aun cuando racionalmente haya tomado la decisión de no llevarla a cabo. Este joven estaría en mucho más riesgo de adoptar esa conducta que uno con una visión prototípica negativa hacia tal conducta $^{10}$. Desde un punto de vista de política pública, los partidarios de este

${ }^{9}$ Por otro lado, modelos racionales sí podrían explicar en parte importante conductas como, por ejemplo, el consumo de drogas (ver por ejemplo, Becker y Murphy, 1988).

10 Éste no es el único modelo dual de comportamiento adolescente. Existen otros, como por ejemplo los derivados de la teoría del "rastro borroso" (o fuzzy trace). En lo más esencial, esta teoría y la del prototipo/disposición son relativamente parecidas. Se 
modelo recomiendan campañas que busquen cambiar estas visiones prototípicas (Reyna y Farley, 2006). De hecho, quienes suscriben esta visión argumentan que su modelo tendría la capacidad de explicar por qué los esfuerzos de política pública que apelan a la racionalidad del joven, buscando mejorar la capacidad de decisión de éste mediante el acceso a información, de manera de facilitarles un proceso de toma de decisión más adecuada, sólo demostrarían en general resultados moderados.

En suma, la literatura aquí sintetizada postula que los comportamientos riesgosos surgirían tanto intencionadamente como no intencionadamente y según sea su origen será también el tipo de intervención que se recomiende. De hecho se argumenta que cuando la conducta tiene un mayor grado de intencionalidad puede ser modificada con información explícita sobre riesgos, beneficios y prevalencia de la conducta. Por ejemplo, en el caso de la actividad sexual, la intervención pasaría por entregar mayor cultura sexual a los jóvenes, informarles detalladamente sobre los riesgos y/o demostrarles que sus creencias sobre la prevalencia de la actividad sexual en sus pares - que afectaría significativamente su propia decisión - podrían estar sobredimensionadas. Por otro lado, la toma de riesgos no intencional es un fenómeno más difícil de afrontar. En general, esta literatura recomienda prevenir las actitudes riesgosas no intencionales con medidas de supervisión adulta y modificación de ambientes, de manera de disminuir las oportunidades para que ocurran las conductas no deseadas. Por ejemplo, Steinberg $(2007,2008)$ argumenta que aumentando el precio de los cigarrillos, implementando medidas más potentes para prohibir la droga, haciendo valer con mayor fuerza las leyes que restringen la edad de los compradores de bebidas alcohólicas, o haciendo más accesibles los condones en lugares de alto riesgo ${ }^{11}$ se

diferencian en el rol que asignan a la intuición en la toma de decisiones. La teoría del "rastro borroso" considera a la intuición como el mecanismo óptimo de toma de decisiones, sosteniendo que quienes la usan (los expertos) comenten menos errores. Este énfasis está ausente en la teoría del "prototipo/disposición”. Estas teorías aplicadas al comportamiento adolescente se encuentran bastante bien descritas en Rivers et al. (2008). También hay diversos modelos racionales que intentarían explicar el comportamiento adolescente, aunque con menos éxito (para una descripción detallada de muchos modelos de comportamiento adolescente, tanto racionales como duales, ver Reyna y Farley, 2006).

${ }^{11}$ Algunas de estas medidas también tienen la particularidad de reducir los costos de protegerse o de aumentar los costos de tomar riesgos, por lo que incluso en contextos puramente racionales de maximización de beneficios tendrían como efecto una disminución en la toma de riesgos. 
podría prevenir algunas de las acciones impulsivas. En Chile, Kruger y Berthelon (2009) argumentan que la extensión de la jornada escolar podría haber reducido la probabilidad de que una joven se embarazara: la explicación que ellos entregan es que al estar más tiempo en la escuela disminuirían las oportunidades de tener encuentros sexuales riesgosos. Algunos investigadores están bastante convencidos de que ese tipo de intervención sería mucho más efectivo que alguno que apuntase a inculcar destrezas racionales de decisión (Reyna y Farley, 2006).

Otras alternativas de políticas que buscan modular aquellos comportamientos de los jóvenes que surgirían de vías no analíticas podrían incluir campañas que busquen modificar las imágenes internas prototípicas de los jóvenes asociadas a ciertas conductas riesgosas. No está de más decir, sin embargo, que este último tipo de intervención representa un desafío a la política pública, ya que es muy posible que muchas campañas que apunten a este objetivo no produzcan los resultados deseados. Cambiar las imágenes mentales de los jóvenes no es una tarea fácil.

Cass Sunstein (2008), activo promotor de la innovación en políticas públicas y quien tiene mucha fe en las propuestas que buscan cambiar los significados sociales de las conductas, sugiere promover la aparición de "empresarios del significado", tanto en la esfera pública como en la privada, que diseñen intervenciones que ayuden a encauzar mejor el comportamiento juvenil. Según su opinión, muchas veces los jóvenes corren riesgos porque creen que sus pares evaluarían una conducta cautelosa como una demostración de cobardía. El problema, a su juicio, sería que los significados sociales no son propiedad de ningún individuo en particular, por lo que cualquier cambio en estos significados requeriría de la solución de un problema de acción colectiva.

Un ejemplo que entrega Sunstein (2008) de un cambio sustancial en el significado social habría sido la importante disminución del consumo de cigarrillos entre la población adolescente afroamericana en los años 70 y 80, hasta un punto en que sólo el 4,4\% de los adolescentes de color fumaba. Esta disminución en el consumo del tabaco no habría tenido paralelo entre la población blanca de Estados Unidos. Según el autor, parte de la explicación del fenómeno estaría en los diferentes significados sociales de fumar, que habría pasado a ser visto por los afroamericanos como una "conducta blanca". Este cambio de percepción se explicaría, al menos de manera parcial, por una campaña priva- 
da en contra del tabaco cuyo principal símbolo estuvo en un póster ampliamente difundido en el tren subterráneo (metro) de Harlem que mostraba un esqueleto que emulaba al hombre Marlboro prendiéndole un cigarrillo a un niño afroamericano. El póster decía "Ellos nos hicieron cosecharlo. Ahora quieren que nos lo fumemos".

La visión de Sunstein no deja de ser controvertida. Hay quienes desconfían enormemente del poder que una campaña puede tener en la mentalidad de un individuo. Sin embargo, el autor también tiene bastantes partidarios y vale la pena mantenerse pendiente de los nuevos desarrollos de un debate que está recién comenzando.

Por otro lado, las teorías recién mencionadas están en continua evolución, alimentadas por nuevos descubrimientos empíricos que van sustentando o refutando sus premisas. Ninguna de estas teorías ha sido comprobada en su totalidad y por tanto el diseño de políticas públicas fundamentadas en sus proposiciones tiene claramente el riesgo de estar basándose en antecedentes erróneos. Sin embargo, en ausencia de un modelo de comportamiento único y comprobado, no nos queda otra opción que basarnos en lo que hoy está disponible: la alternativa, poco recomendable, sería quedarnos de brazos cruzados hasta tener las certezas que quién sabe cuándo lograremos alcanzar. En ese sentido, es importante, desde un punto de vista de política pública, ir evaluando cada una de las innovaciones que se van haciendo a fin de aprovechar las iniciativas exitosas de mejor manera y desechar las ideas que demuestren poca o nula efectividad.

En este artículo nos centramos en uno de estos comportamientos riesgosos específicos: la actividad sexual de los jóvenes. Cuando la actividad sexual se realiza de manera poco consciente, las consecuencias pueden ser negativas: con el sida y otras enfermedades de transmisión sexual y el embarazo como potenciales consecuencias que pueden marcar al o a la joven por el resto de su vida (y no nos olvidemos de ese niño que nace en condiciones posiblemente desventajosas).

\section{COMPORTAMIENTO SEXUAL ADOLESCENTE, EMBARAZO Y ETS EN CHILE Y EL MUNDO}

En Chile las tasas de fecundidad adolescente han ido decreciendo en el tiempo, como lo muestra la Tabla $N^{\circ} 1$. Las tasas de fecundidad están muy relacionadas con las tasas de comportamientos sexuales 
TABLA N ${ }^{\circ}$ 1: $\quad$ NATALIDAD Y TASA DE FECUNDIDAD ESPECÍFICA EN ADOLESCENTES DE 10-14 AÑOS Y 15-19 AÑOS, CHILE 1990-2005

\begin{tabular}{lrrrcrc}
\hline \multicolumn{3}{c}{ 10-14 años } & & & $15-19$ años \\
Año & PE & NV & TF \%o & PE & NV & TF\%o \\
& & & & & & \\
\hline 1990 & 589.180 & 742 & 1,26 & 609.389 & 39.543 & 64,9 \\
1995 & 632.708 & 1.033 & 1,63 & 597.333 & 37.852 & 63,4 \\
2000 & 700.684 & 1.055 & 1,51 & 629.166 & 39.257 & 62,4 \\
2005 & 731.237 & 935 & 1,28 & 719.637 & 35.143 & 48,8 \\
& & & & & & \\
\hline
\end{tabular}

PE: población estimada. NV: nacidos vivos. TF: tasa de fecundidad (x 1.000 mujeres)

Fuente: Donoso, 2008.

riesgosos entre los jóvenes, ya que en ese rango etario los embarazos son en general no deseados ${ }^{12}$. Estas tasas de fecundidad adolescente nos ubican en el nivel más bajo de la región (ver Figura $\mathrm{N}^{\circ} 1$ ).

Sin embargo, esta comparación no debe llevarnos a suponer que el problema del embarazo adolescente es un asunto de dimensiones menores en nuestro país. Las tasas de nacimientos en madres adolescentes en Sudamérica se caracterizan por ser muy altas, superiores a las del mundo desarrollado, donde en general no se sobrepasa los 25 nacimientos por 1.000 adolescentes. Notables son los casos de Dinamarca, Noruega, Suecia, Italia, Eslovenia, Bélgica, Francia, Países Bajos, Suiza, Japón, Singapur y Corea del Sur, cuyos índices son inferiores a los 10 nacimientos por cada 1.000 adolescentes (Naciones Unidas, 2007). Es cierto que las cifras de los países desarrollados están afectadas por el hecho de que en ellos el aborto es legal ${ }^{13}$, por lo que muchas jóvenes no llevan a término sus embarazos, afectando así las cifras de nacimientos. Sin embargo, como veremos más adelante, las cifras de abortos realizados en estos países están disponibles y nos muestran que, aun sumando abortos con embarazos que llegan a término, las tasas de embarazos adolescentes en los países desarrollados son muy inferiores a las de nuestro país.

${ }^{12}$ Se puede argumentar que en pobreza algunas adolescentes buscarían explícitamente embarazarse. Sin embargo, como veremos más adelante, en los sectores socioeconómicos bajos el número de mujeres que reportan haber tenido embarazos no deseados es muy alto, y significativamente superior al de los estratos más acomodados.

${ }^{13}$ Aunque no podemos olvidar tampoco que el aborto ilegal es una realidad en países como el nuestro. 
FIGURA N ${ }^{\circ}$ 1: $\quad$ TASA DE FECUNDIDAD ADOLESCENTE EN SUDAMÉRICA HIJOS NACIDOS VIVOS POR CADA 1.000 ADOLESCENTES DE 15 A 19 AÑOS

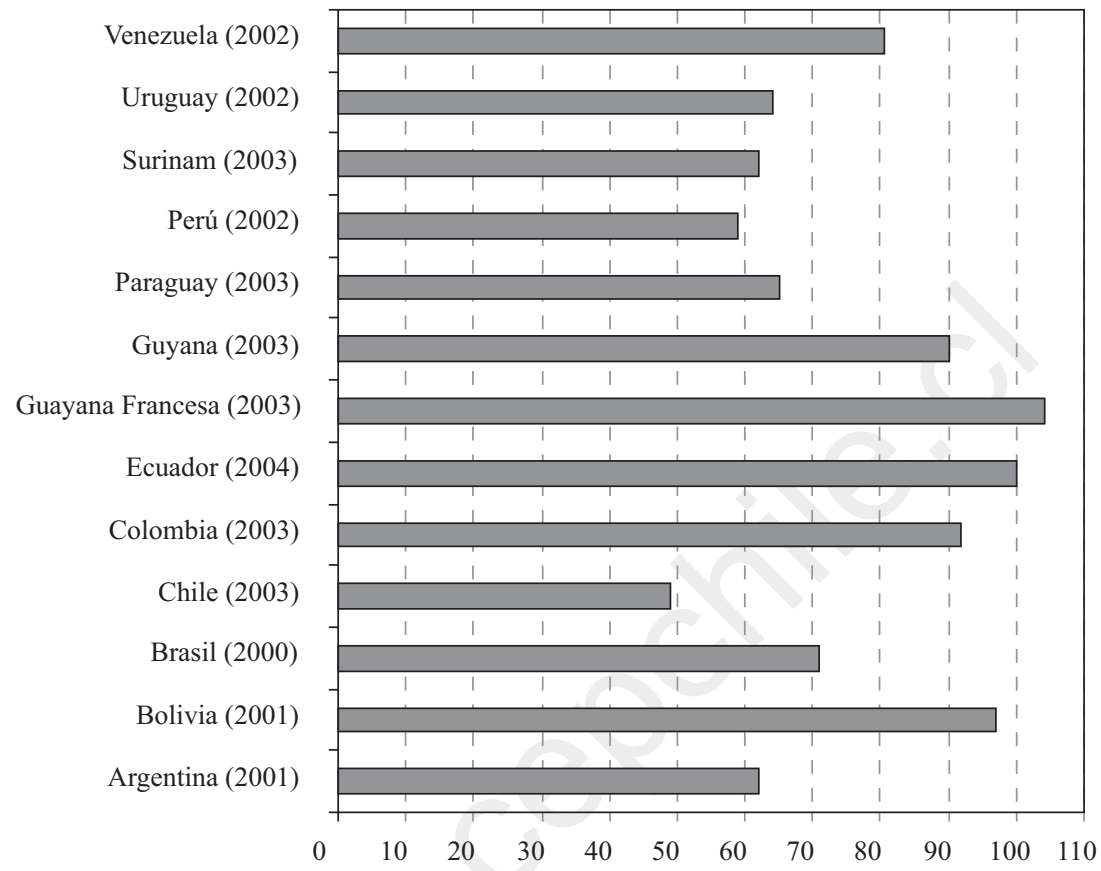

Fuente: Naciones Unidas (2007).

Una excepción a la regla en los países desarrollados es Estados Unidos. Con una tasa de embarazo adolescente de 41 por cada 1.000 en 2004 y una tasa de abortos bastante alta de 19,8 por cada 1.000 adolescentes ${ }^{14}$, el embarazo adolescente sigue considerándose en ese país como un problema de salud pública. De hecho, la tasa de fecundidad adolescente en Estados Unidos de 2007 (42,5 por 1.000) fue más de cuatro veces la de Alemania de ese año (9,6 por 1.000), casi seis veces la de Francia (7,1 por 1.000) y casi nueve veces la de Países Bajos (4,8 por 1.000). Al mismo tiempo la tasa de abortos de los Estados Unidos supera con creces a la de estos tres países ${ }^{15}$ (Advocates Youth, 2009.

${ }^{14}$ Los datos de embarazos son de Kirby (2007) y los de aborto de Advocates for

${ }^{15}$ La tasa para Estados Unidos en 2004 fue de 19,8 abortos por cada 1.000 adolescentes, un 35\% más que la de Francia, que alcanzó los 14,6 abortos por cada 1.000, y más que duplicó la de Alemania (7,2 por 1.000) y la de Países Bajos (7,8 por 1.000). 
for Youth, 2009). Una comparación similar se puede hacer respecto de la prevalencia de enfermedades de transmisión sexual (ETS) en Estados Unidos versus en los países europeos recién mencionados. La prevalencia de VIH en Estados Unidos en 2007 (0,6\%) excede en 50\% la de Francia $(0,4 \%)$, triplica la de Países Bajos $(0,2 \%)$ y sextuplica la de Alemania $(0,1 \%)$. Lo mismo ocurre con enfermedades como la sífilis, gonorrea y clamidia, que son mucho más prevalentes en Estados Unidos (Advocates for Youth, 2009). Por otro lado, los jóvenes norteamericanos que han comenzado su actividad sexual tienen más de una pareja por año con mayor frecuencia que sus contrapartes de otros países desarrollados (Darroch et al., 2001). Aunque la edad mediana de iniciación sexual es similar entre países (Darroch et al., 2001), la edad promedio es significativamente más temprana en los Estados Unidos (Berne y Huberman, 1999). Es importante dejar claro que estas comparaciones se basan en estudios que contrastan la realidad de los Estados Unidos con los países cuyas estadísticas del comportamiento sexual riesgoso en adolescentes muestran que es un modelo a seguir. Otros países europeos tienen estadísticas bastante menos alentadoras que las de los países aquí mencionados. Aun así las estadísticas norteamericanas son peores que las de la gran mayoría de los países de la región.

¿Por qué la brecha entre Estados Unidos y los países desarrollados? Evidencia de estudios comparados

La visión del problema ha incentivado variadas iniciativas de investigación que buscan dilucidar el porqué de la enorme brecha entre Estados Unidos y otros países desarrollados. De partida se ha establecido que en Estados Unidos la prevalencia en el uso de anticonceptivos hormonales sería bastante inferior a la de sus contrapartes. En general la prevalencia del condón como método primario de anticoncepción en Estados Unidos podría explicar en parte la divergencia en tasas de embarazos entre países, ya que en los países europeos los métodos primarios de anticoncepción serían mayormente los métodos hormonales, que son más efectivos y tienen efectos de protección permanentes cuando se usan de manera correcta. Por otro lado, en los países europeos el uso de condón sería relativamente común, pero en general como complemento (y no sustituyendo) a los métodos hormonales. En Estados Unidos, además, el sexo desprotegido sería, al parecer, mucho 
más prevalente entre adolescentes que en los otros países estudiados (en este caso, Suecia, Francia, Canadá y Gran Bretaña: Darroch et al., 2001).

Algunas de las iniciativas de investigación que han buscado una explicación para la divergencia entre el comportamiento sexual riesgoso en adolescentes norteamericanos versus sus contrapartes del mundo desarrollado han concluido que los países europeos difieren de Estados Unidos en la apertura social a los temas sexuales de los jóvenes y en el uso de herramientas gubernamentales pragmáticas (Advocates for Youth, 2009). Como se mencionó con anterioridad, se argumenta que en esos países se habría logrado que el uso de anticonceptivos orales sea mayor que en Estados Unidos y además la doble protección (anticonceptivo hormonal junto con condón) sería más prevalente. La investigación argumenta que aparentemente estos países basarían sus políticas públicas relativas a prevención de embarazos y ETS en los resultados y conclusiones de la investigación científica, y no estarían sujetos a presiones significativas por grupos políticos o religiosos. Según el estudio mencionado, estas naciones aplican políticas con objetivos reconocidos: reducir el número de abortos y embarazos no deseados y prevenir las enfermedades de transmisión sexual. Para ello, a diferencia de Estados Unidos, sus políticas nacionales se enfocan en asegurar el acceso oportuno de los jóvenes a métodos anticonceptivos, a educación sexual consistente y a campañas públicas de gran alcance a través de los medios. Estas campañas serían directas, con sentido del humor, y se focalizan en la seguridad y en el placer ${ }^{16}$. En general en estos países la educación sexual no es un programa separado del currículum escolar. Al parecer, los temas sexuales se integran generalmente en las escuelas a través de las distintas asignaturas y a lo largo de todos los cursos. Los educadores proveen información precisa y completa en respuesta a preguntas de los alumnos ${ }^{17}$. En estos países, las familias estarían acostumbradas a tener conversaciones abiertas y honestas sobre sexualidad con sus hijos y apoyarían el rol de los educadores y servicios de salud en su entrega de información accesible a los adolescentes. Según algunos estudios, los adultos europeos verían

\footnotetext{
${ }^{16}$ Ver, por ejemplo, Berne y Huberman, 1999, para una descripción de esas campañas en Alemania, Países Bajos y Francia.

${ }^{17}$ Ver, por ejemplo, Weaver et al., 2005, para una descripción en mayor detalle de las intervenciones de educación sexual a nivel escolar en distintos países.
} 
la iniciación de relaciones sexuales íntimas de sus hijos como una etapa adecuada en el desarrollo de los adolescentes mayores, y lo percibirían como un componente positivo para una maduración saludable. Al mismo tiempo, se argumenta que los adolescentes europeos considerarían “estúpido e irresponsable” el tener sexo sin protección ${ }^{18}$. Los jóvenes en general tendrían inscrito en sus códigos de comportamiento la máxima de safe sex or no sex ${ }^{19}$. Las sociedades europeas que se analizan, al parecer, sopesan la moralidad de la conducta sexual a través de una ética individual que incluye los valores de la responsabilidad, respeto, tolerancia y equidad ${ }^{20}$. Así, la visión europea calificaría que, tal como la sociedad tiene la responsabilidad de entregar a los jóvenes las herramientas que ellos necesitan para mantener una adecuada salud sexual, los jóvenes por su parte serían los responsables de protegerse de embarazos no planificados o de enfermedades de transmisión sexual (Advocates for Youth, 2009).

Sin embargo, estos trabajos que buscan comparar la realidad europea con la norteamericana a veces olvidan ciertas diferencias fundamentales entre los distintos países que podrían explicar de manera importante por qué las iniciativas de una educación sexual coherente han fructificado en Europa y no en Estados Unidos. De partida, la Europa central y del norte es mucho más secular ${ }^{21}$ que Estados Unidos (y por cierto también que Chile). Por otro lado, Estados Unidos (y también Chile) son países que se caracterizan por su enorme desigualdad. Es posible que esa desigualdad produzca una sociedad fragmentada en la que distintos grupos responderían de manera diferente a distintas intervenciones. En esos ambientes podría ser recomendable diseñar varios programas focalizados en cada uno de estos grupos. Por otro lado, en una sociedad homogénea es mucho más probable que un solo programa sea efectivo para toda la población. De hecho, el nivel so-

${ }^{18}$ En ese sentido, y a la luz de los modelos psicológicos descritos previamente, se podría argumentar que en los países europeos se ha establecido una visión prototípica muy negativa del sexo sin protección. Esto llevaría a que a los jóvenes de esas latitudes les fuese más fácil controlarse y abstenerse en casos donde el riesgo es alto.

${ }^{19}$ Sólo tengo sexo si es seguro. Si no, me abstengo.

${ }^{20}$ Para mayor información sobre las diferencias entre las aproximaciones norteamericanas y las de otros países desarrollados a la problemática de la conducta sexual riesgosa de los jóvenes, ver Advocates for Youth (2009), Berne y Huberman (1999), Darroch et al. (2001) y Weaver et al. (2005).

${ }^{21}$ En el sentido de que hay menor presión de grupos religiosos con ideas particulares respecto de una serie de temas valóricos, entre ellos el cómo deben tratarse los temas asociados al sexo. 
cioeconómico es un predictor relativamente importante del comportamiento sexual de los adolescentes y del tipo de hogar en que éstos crecen (que a su vez es un buen predictor de su comportamiento sexual). Además, es posible que la ausencia o menor prevalencia de grupos severamente desaventajados en Europa que en Estados Unidos sea una razón determinante para explicar las diferencias en el comportamiento sexual de sus jóvenes. En ese sentido, Chile se parece más a Estados Unidos que a los países europeos evaluados en los estudios.

\section{Programas de prevención: Una alternativa de política}

Otra línea de investigación muy activa en Estados Unidos, debido a las dificultades que ha tenido en el tema la prevención de embarazos adolescentes y ETS, es la que busca evaluar la efectividad de distintos programas educativos diseñados para disminuir el nivel de riesgo de las conductas sexuales de los jóvenes. Un resumen y evaluación de la evidencia recogida hasta hace poco se encuentra en Kirby $(2007)^{22}$. El estudio recién mencionado, cuyo foco se restringió a experiencias realizadas dentro de los Estados Unidos, entrega un recuento bastante interesante de las variables que han demostrado incidir en el comportamiento riesgoso de los jóvenes y las características distintivas de las intervenciones que han tenido mejores resultados ${ }^{23}$.

En general, existen muchos programas de educación sexual que han tenido variados niveles de éxito en Estados Unidos. Los programas se pueden dividir entre aquellos que enfatizan abstinencia y los programas integrales, que además de buscar que los jóvenes retarden su iniciación sexual, les entregan las herramientas para que, en caso de tener una vida sexual activa, se protejan de manera adecuada. Estos últimos programas han mostrado hasta ahora bastante más eficacia que los primeros, tanto en el objetivo de retrasar la iniciación como en el de prevenir potenciales embarazos o ETS $^{24}$. Sin embargo, aun así los

${ }^{22}$ Otro resumen de la literatura bastante extenso y que contiene la descripción de varias iniciativas que han sido evaluadas positivamente es el realizado por Advocates for Youth (2008).

${ }^{23} \mathrm{El}$ autor entrega una lista de los 17 factores que se ha demostrado deben tomarse en cuenta al momento de diseñar una intervención para que ésta sea efectiva.

${ }^{24}$ Kirby (2007), sin embargo, es cauto en su apreciación de los programas enfocados en la abstinencia, ya que no son suficientes las experiencias de este tipo evaluadas. En ese sentido el autor acota que en el campo de la investigación de la efectividad de programas de abstinencia hay todavía bastante espacio para investigar. 
programas más exitosos tendrían una efectividad relativamente limitada (30 a 50\% de disminución de los índices objetivos del programa). Kirby destaca varios programas integrales cuyos resultados fueron bastante alentadores. Uno de éstos, enfocado a la reducción del embarazo adolescente y de ETS con bastantes buenos resultados, y cuyo grupo objetivo incluía población latina, es el programa Reducing the Risk: Building Skills to Prevent Pregnancy, STD\&HIV. Este programa tiene la ventaja de haber logrado retrasar la iniciación sexual de los jóvenes, y a la vez de haber aumentado el uso del condón y de los métodos hormonales y de haber disminuido la incidencia de sexo desprotegido entre aquellos jóvenes que ya habían comenzado su actividad sexual. Además el programa tiene la gracia de haber mantenido sus efectos al ser replicado en poblaciones diferentes. Reducing the Risk consiste en 16 sesiones de 45 minutos realizadas en la escuela, y su objeto es entregar a los jóvenes información sobre los riesgos del sexo desprotegido, y también enseñarles destrezas sociales que les permitan rechazar potenciales encuentros no deseados o muy riesgosos, responder de manera efectiva a presión de pares o pareja ${ }^{25}$, etc. Kirby (2007) y Advocates for Youth (2008) mencionan otros varios programas exitosos, por lo que se recomienda al lector interesado acudir directamente a esas fuentes. Cuál de los programas exitosos es el más aconsejable para emular depende de los objetivos particulares del programa y también de las características de la población a capacitar.

Como se explicó más arriba, Kirby (2007) reporta que los programas cuyo foco está puesto exclusivamente en la abstinencia en general no han mostrado resultados alentadores. Sin embargo, el autor reconoce que son muy pocos los estudios de buena calidad que han evaluado este tipo de programas, por lo que se hace necesario seguir investigando en esta línea antes de emitir conclusiones definitivas. En ese sentido, un estudio muy reciente (Jemmott et al., 2010) hace un aporte interesante. La evaluación realizada por los autores tiene la ventaja de haber sido diseñada como un estudio experimental. En éste se comparan los efectos de dos intervenciones integrales de distinta duración, una intervención informativa sobre uso de condón solamente y una intervención que se centraba exclusivamente en la abstinencia (además de un grupo de control). Los resultados en este caso fueron

${ }^{25}$ Ver por ejemplo http://www.etr.org/traininginstit/rtr.htm para una breve descripción del programa y sus objetivos. 
claramente favorables a la intervención asociada con la abstinencia. Sin embargo, los autores enfatizan que el programa de abstinencia en cuestión difería de los programas de abstinencia "típicos" en que no contenía información desacreditando el uso del condón, no presentaba el sexo como algo negativo ni usaba tonos moralísticos. La intervención en particular incluyó información sobre riesgos de sida y enfermedades de transmisión sexual y buscó reforzar la creencia de que la abstinencia prevenía los riesgos de estas enfermedades o el embarazo, por lo que la ausencia de actividad sexual podría permitir la consecución de los objetivos futuros de los jóvenes. Finalmente el programa buscó enseñar destrezas para negociar la abstinencia y resistir las presiones para tener sexo. El mensaje contenido en la intervención se centraba en retrasar lo más posible la iniciación sexual, pero no estresaba la importancia de esperar hasta el matrimonio. Es importante recalcar que la intervención en cuestión no afectó negativamente - como algunos detractores de estas intervenciones postularían- la incidencia del uso del condón.

Embarazo adolescente y ETS: Factores de riesgo y factores protectores

Kirby (2007) enumera los factores familiares, ambientales y personales que han demostrado incidir más en el embarazo adolescente. Los factores los separa en "factores de riesgo" y "factores protectores" según si promueven u obstaculizan la conducta considerada óptima. Así, los "factores protectores" tenderían a retardar la iniciación sexual, a incrementar el buen uso de métodos anticonceptivos y de prevención de ETS para los ya iniciados, a disminuir el número de parejas sexuales y a disminuir la frecuencia del sexo y la probabilidad de tener sexo desprotegido. Por otro lado, los "factores de riesgo" actuarían en la dirección opuesta. Entre los factores que se habría demostrado que inciden en el comportamiento sexual adolescente están los asociados a la comunidad donde vive el joven (donde los factores de riesgo serían la desorganización, violencia, uso de drogas, etc.), factores asociados a la estructura familiar (donde los riesgos surgirían en familias donde hay divorcios o madres solas), educación de los padres (mientras mayor es ésta, mayor es el nivel de protección), uso de drogas por el adolescente o por personas dentro del hogar (aumentan el riesgo), dinámicas familiares y apego (factores protectores, que incluyen el adecuado nivel de supervisión del adolescente), actitudes familiares respecto del sexo y el embara- 
zo adolescente ${ }^{26}$, comunicación sobre sexo y anticoncepción (que sería especialmente protector si se da de manera previa a que el adolescente comience su actividad sexual), actitudes y creencias de los pares ${ }^{27}$, características de la pareja (mientras mayor es ésta, mayor es el riesgo; por otro lado una pareja que apoya el uso de condón o anticonceptivos actúa como factor protector), y características individuales como sexo, edad y madurez biológica, desempeño escolar ${ }^{28}$, apego a la comunidad y religiosidad. Otros factores de riesgo importantes en la determinación de las conductas sexuales del joven incluyen pertenecer a una pandilla, portar armas, problemas de delincuencia y el abuso del alcohol o drogas. Respecto del estatus laboral, trabajar más de 20 horas semanales se considera un factor de riesgo, mientras que hacer deportes ha probado ser protector, por lo menos para las mujeres. La depresión y pensamientos suicidas habrían mostrado determinar conductas sexuales riesgosas en adolescentes, y las distintas actitudes frente al sexo ${ }^{29}$ también afectarían la conducta de éstos. Se ha comprobado también que las relaciones de pareja influirían, siendo un factor de riesgo el tener citas con mayor frecuencia, tener pololo o "andante", tener alta frecuencia sexual, mayor número de parejas, un embarazo previo, historia de abuso sexual, o atracción por personas del mismo sexo. Factores protectores incluirían una mayor edad al momento de tener la primera relación sexual voluntaria, comunicación de riesgos sexuales con la pareja e historia de uso efectivo de condón u otros métodos de anticoncepción.

${ }^{26}$ Donde la presencia de madres que se iniciaron tempranamente y tuvieron hijos en la adolescencia sería un factor de riesgo, la desaprobación del sexo antes del matrimonio o durante la adolescencia sería un factor protector, como también la aceptación y apoyo familiar al uso de métodos anticonceptivos para jóvenes activos sexualmente.

${ }^{27}$ En general, los factores de riesgo incluyen pares o amigos cercanos que consuman alcohol o drogas, que sean activos sexualmente, pares que tengan actitudes o creencias favorables sobre el embarazo adolescente y valores permisivos sobre el sexo. Por otro lado, factores protectores incluyen a pares con normas favorables al uso de anticonceptivos o condones o pares que usan condones.

${ }^{28}$ Mejor desempeño es protector, como también una buena conexión con la escuela y altas aspiraciones educacionales y planes para el futuro.

${ }^{29}$ Actitudes más permisivas son factores de riesgo mientras que los factores protectores incluyen el hacer promesa de virginidad, la percepción de responsabilidad masculina frente a un eventual embarazo, percepciones y creencias de que el uso del condón no reduce el placer sexual, mayor motivación hacia el uso del condón u otro método anticonceptivo, percepciones más negativas sobre las consecuencias de un embarazo, motivación para evitar embarazo y ETS, entre otras (Kirby, 2007). 
Los factores recién mencionados, según Kirby (2007), tendrían un alto potencial de causalidad. El autor menciona que al momento de hacer el recuento de la investigación hasta la fecha de publicación de su informe, sólo consideró aquellos estudios que tienen una metodología tal que permite inferir algún tipo de relación causal entre factor y resultado. Por consideraciones de tiempo, no hemos investigado hasta qué punto esta aseveración es verdadera. La tarea de demostrar fehacientemente la causalidad no es fácil, por lo que se recomienda cautela frente a la evidencia recopilada. Consideraciones aparte, el lector ya habrá notado que algunos de los factores mencionados en Kirby (2007) son modificables a través de esfuerzos de política pública, y otros no lo son o lo son pero con un nivel de dificultad mayor. Más adelante en este trabajo realizaremos un análisis econométrico cuyo objetivo será establecer, al menos de manera inicial, cómo algunos de estos factores afectan el comportamiento sexual de los jóvenes chilenos. Esto nos permitirá avanzar en el proceso de verificar si la literatura recién descrita tiene alguna aplicación en el contexto de nuestro país y por lo tanto nos ayudará en la tarea de proponer políticas para ayudar a nuestros jóvenes a moderar el nivel de riesgo sexual que toman.

Otras políticas que podrían tener efectos en los costos del comportamiento sexual riesgoso

Un estudio reciente que evalúa las conductas sexuales riesgosas de los jóvenes en Estados Unidos es el de Levine (2001). El objetivo del autor era establecer los determinantes del comportamiento sexual juvenil y estimar hasta qué punto estos jóvenes responden a los costos asociados a sus conductas. Su análisis estudió los efectos asociados a cambios en las políticas de bienestar (asociadas a maternidad adolescente) en ese país. Los resultados reportados por el autor indican que, aunque los adolescentes son algo sensibles a los costos de la maternidad adolescente, el efecto es acotado. De hecho, el artículo reporta que en Estados Unidos el 95 por ciento de las jóvenes sabe que pueden quedar embarazadas en su primera relación sexual, y el 80 por ciento sabe que pueden conseguir anticoncepción gratis o muy barata en los consultorios. Sin embargo, en ese país la prevalencia del sexo sin protección es, como mencionamos anteriormente, todavía bastante alta, con el consiguiente alto nivel de embarazos adolescentes. 
En la línea de las políticas que buscan, entre otras cosas, cambiar los "costos" de las conductas sexuales riesgosas están aquellas que aumentan o disminuyen los beneficios de la seguridad social para madres solteras o aquellas que buscan cambiar los costos para los padres de los niños. En esa última línea se encuentra la reciente iniciativa implementada en Costa Rica a través de su "ley de paternidad responsable”. En caso de nacimientos fuera del matrimonio, esta ley establece que la madre tiene la facultad de indicar el nombre del progenitor, el cual es citado y cuenta con diez días para negar o afirmar la paternidad. En caso de negar su posible paternidad debe someterse a un estudio de ADN. Cuando el padre no acepta participar en el estudio de ADN o cuando no se apersona luego de la citación, la presunción de paternidad opera automáticamente, lo que implica que dicha persona queda obligada por ley al pago de alimentos y al reembolso de gastos por embarazo y por cuidados de los primeros doce meses del niño (Lupica 2009). El efecto de esta iniciativa en el comportamiento sexual de los jóvenes costarricenses no ha sido evaluado aún. Sin embargo, iniciativas similares (pero menos extremas) realizadas en Estados Unidos mediante los programas de Child Support Enforcement y Paternity Establishment han mostrado tener algunos efectos en la tasa de embarazos adolescentes de ese país. El programa de Child Support Enforcement tiene como objetivo mejorar la recolección de fondos entre los padres que no viven con sus hijos. Una (de las varias) manera de lograr ese objetivo es a través de facilitar el proceso de verificación de paternidad. Este último objetivo es el que persigue el programa de Paternity Establishment de ese país (para una descripción en profundidad de estos programas ver Pirog y Ziol-Guest, 2006, y Solomon-Fears, 2002). Este programa ha tenido bastante éxito. En 1979 sólo el 19\% de los nacimientos fuera del matrimonio en Estados Unidos tenía reconocimiento paterno. Esta cifra aumentó a 52\% en 1996. Esto, junto a las mejores herramientas para exigir el cumplimiento de las obligaciones legales de los padres en temas de alimentos, ha resultado al parecer en un aumento sustancial de los pagos (McLanahan y Carlson, 2002).

Desde un punto de vista teórico, estos programas incrementarían para los padres los costos de embarazar a sus parejas, lo que desincentivaría la toma de riesgos por parte de los hombres. Sin embargo, los mismos programas incentivarían la toma de riesgo por parte de las mujeres, quienes percibirían la maternidad como menos costosa. 
Desde un punto de vista empírico, los estudios sugieren que el efecto de estas políticas en hombres supera el efecto en las mujeres, llevando a un efecto neto donde el embarazo fuera del matrimonio desciende, $\mathrm{y}$ también descienden los divorcios (Seltzer et al., 1998, Aizer y McLanahan, 2006, Plotnik et al., 2006 y Nixon, 1997). Es fundamental dejar en claro que las políticas recién enunciadas no tienen como objetivo principal la disminución del embarazo adolescente o fuera del matrimonio. Este objetivo, sin embargo, se logra en alguna medida aunque los efectos reportados por los estudios son relativamente pequeños. Políticas de este tipo por lo tanto podrían, sin embargo, ser recomendables desde más de un punto de vista, al servir tanto como desincentivos parciales a la fertilidad adolescente como para mejorar el bienestar infantil y materno, a su vez que logran responsabilizar a los padres al menos en su rol de proveedores ${ }^{30}$. En Chile se ha avanzado bastante en este flanco, pero es posible que exista aún espacio para mejorar las políticas de paternidad responsable.

\section{EL COMPORTAMIENTO SEXUAL DE LOS JÓVENES CHILENOS}

La base de datos que se utilizará para los análisis del comportamiento sexual de los jóvenes en Chile es la Quinta Encuesta Nacional de Juventud (ENJ), diseñada por el Instituto Nacional de la Juventud y aplicada durante los meses de noviembre y diciembre del 2006. Esta encuesta, entre otras cosas, nos entrega una radiografía del comportamiento sexual de los jóvenes chilenos de entre 15 y 29 años. Lamentablemente la encuesta no incluye a jóvenes menores de esa edad, que son justamente aquellos para quienes las consecuencias de un embarazo precoz resultan más complicadas tanto física como psicológicamente.

Para los efectos de los análisis que se realizarán a continuación sólo se tomará en cuenta el subgrupo de los menores de 24 años. Se tomó esa decisión ya que suponemos que una parte importante de los

\footnotetext{
${ }^{30}$ Estas políticas también pueden haber afectado el nivel de involucramiento afectivo de los padres con sus hijos. Esto puede ocurrir porque padres que se ven obligados a mantener a sus hijos querrían conocer más sobre cómo se gastan los recursos. Esto los llevaría a mantener un mayor nivel de comunicación con sus hijos, lo que eventualmente se traduciría en un involucramiento afectivo. Argys y Peters (2001) demostrarían que los programas recién mencionados en Estados Unidos habrían tenido efectos en la línea recién mencionada.
} 
jóvenes mayores ya habrían adquirido el grado de madurez psicosocial adecuado que les permita tomar decisiones similares a las de los adultos en lo que se refiere a nivel de riesgo. De hecho nosotros queremos cuantificar específicamente el comportamiento de quienes aún no han alcanzado la adultez ${ }^{31}$. Se excluyen además de la muestra a aquellos jóvenes que tienen una relación de convivencia o matrimonio y a aquellos que dicen estar buscando un embarazo. El nivel de "riesgo" que involucra no tomar precauciones cuando existe el soporte económico y emocional inherente a una gran proporción de las parejas en convivencia estable es muy distinto del asociado a las conductas de jóvenes que aún no han adquirido la suficiente independencia. Por otro lado sólo cuando la posibilidad de embarazo es no deseada podemos considerar una conducta sexual descuidada como riesgosa. Todas las tablas que se presentarán a continuación utilizan estas submuestras como base de análisis, a menos que se diga explícitamente lo contrario.

La Tabla $\mathrm{N}^{\circ} 2$ nos muestra la proporción de jóvenes menores de 24 años $^{32}$ que han iniciado su actividad sexual, según sexo y edad. También entrega información sobre si los jóvenes que son activos sexualmente se cuidaron en la última relación. Por "cuidado en la última relación" nos referimos a quienes respondieron "sí" a esa pregunta, sin preocuparnos de evaluar el tipo de método utilizado y su efectividad. Esa información la recogemos en la Tabla $\mathrm{N}^{\circ} 3$ que desglosa los métodos utilizados ${ }^{33}$. Lamentablemente el método reportado por cada joven corresponde sólo al método "principal" utilizado. No tenemos información sobre el uso simultáneo de dos o más métodos. Las tablas recién mencionadas nos entregan bastante información interesante:

- $\quad$ La mayoría de los jóvenes mayores de 18 años ya ha comenzado su actividad sexual. Quienes no han alcanzado la mayoría de

${ }^{31}$ Por adultez aquí no nos referimos a un estatus legal sino a un estado de madurez relativamente completo. En estricto rigor no existe una clara frontera etaria entre adolescencia y adultez, y de hecho distintos individuos alcanzan la madurez a distintas edades. Frente a la necesidad de establecer un punto de corte decidimos que sean los 23 años (inclusive), basándonos en la evidencia documentada (por ejemplo por Steinberg, 2007, 2008) de que los jóvenes en edad universitaria tienen una mayor propensión al riesgo que los jóvenes de mayor edad (que en general no se diferenciarían demasiado de los adultos).

${ }^{32}$ Excluyendo casados o en relación de convivencia, y a aquellos que buscan embarazo.

${ }^{33}$ La pregunta sobre la que se basa la Tabla $N^{\circ} 3$ busca conocer si alguien en la pareja se protegió para evitar un embarazo. Por eso aparecen hombres diciendo que utilizaron la píldora como protección: fueron sus parejas las que se cuidaron. 
TABLA N 2: $\quad$ INICIACIÓN SEXUAL DE JÓVENES SEGÚN EDAD Y SEXO

\begin{tabular}{|c|c|c|c|c|}
\hline \multirow[t]{2}{*}{ Edad } & \multicolumn{2}{|c|}{$\begin{array}{c}\text { Comenzó su actividad } \\
\text { sexual (\%) }\end{array}$} & \multicolumn{2}{|c|}{$\begin{array}{l}\text { Cuidado última relación } \\
\text { (sólo activos, \%) }\end{array}$} \\
\hline & Hombre & Mujer & Hombre & Mujer \\
\hline $15-16$ & 22,10 & 15,18 & 63,32 & 59,45 \\
\hline $17-18$ & 55,44 & 43,97 & 64,96 & 65,18 \\
\hline $19-20$ & 81,43 & 65,00 & 76,68 & 78,57 \\
\hline $21-23$ & 88,71 & 79,23 & 76,31 & 83,15 \\
\hline Total & 61,13 & 49,42 & 72,65 & 76,11 \\
\hline
\end{tabular}

TABLA N ${ }^{\circ}$ 3: $\quad$ MÉTODO DE CUIDADO EN ÚLTIMA RELACIÓN SEXUAL, \% (SÓLO QUIENES SE CUIDARON)

\begin{tabular}{|c|c|c|c|c|c|c|c|c|}
\hline \multirow[b]{2}{*}{ Edad } & \multicolumn{4}{|c|}{ Hombres } & \multicolumn{4}{|c|}{ Mujeres } \\
\hline & Condón & DIU & Píldora & Otros ${ }^{*}$ & Condón & DIU & Píldora & Otros* \\
\hline $15-16$ & 91,06 & 0 & 6,60 & 2,34 & 71,90 & 7,78 & 17,99 & 2,33 \\
\hline $17-18$ & 79,90 & 2,12 & 16,99 & 0,99 & 53,94 & 3,63 & 36,88 & 5,55 \\
\hline $19-20$ & 70,75 & 3,10 & 23,76 & 2,39 & 43,02 & 10,11 & 43,52 & 3,35 \\
\hline $21-23$ & 67,07 & 4,28 & 26,10 & 2,55 & 38,30 & 10,77 & 46,85 & 4,08 \\
\hline Total & 72,78 & 3,12 & 21,92 & 2,18 & 44,69 & 9,11 & 42,17 & 4,03 \\
\hline
\end{tabular}

* Incluye píldora del día después, diafragma/espermicida, coito interrumpido, métodos naturales, inyectables y a quienes no responden la pregunta. De estas opciones la más prevalente son los inyectables.

edad también tienen un nivel de actividad significativo, especialmente a partir de los 17 años.

- Aunque el rango etario de los 15 a los 16 años es el menos activo, este grupo (y probablemente los menores de 15 también) tiene bastante relevancia desde el punto de vista de la política pública, dado que es el que menos utiliza métodos de prevención de la natalidad y ETS. Aunque son menos los iniciados a esta edad, la probabilidad de embarazo en ellos es muy alta, y los embarazos a esas edades tienen más consecuencias negativas que los embarazos en jóvenes de más edad. Es interesante notar que incluso aquellos jóvenes de 15 y 16 años que reportan haber 
utilizado algún método han usado principalmente el condón que, aunque es el método más protector frente a las ETS, tiene la desventaja de que la protección frente al embarazo no es permanente. En ese sentido, un joven que se cuidó hoy con condón puede que mañana tenga un encuentro sexual completamente desprotegido, riesgo que disminuye cuando el método elegido tiene efectos más duraderos ${ }^{34}$.

- $\quad$ Al parecer los hombres son más precoces que las mujeres en su iniciación sexual ${ }^{35}$. Además, los hombres más jóvenes tienden a ser más precavidos que las mujeres más jóvenes, tendencia que se revierte en quienes tienen 19 años y más.

- $\quad$ El condón es el método más prevalente de prevención utilizado por los jóvenes, sin importar la edad. Entre las mujeres más jóvenes el condón es también el método más utilizado, pero esta tendencia se revierte en favor de la píldora para las mujeres de más edad.

- $\quad$ Si miramos el comportamiento preventivo de las jóvenes nos damos cuenta de que hay una significativa evolución con la edad. Las mujeres mayores tienen muchas más probabilidades de cuidarse y utilizan en mayor grado los métodos hormonales. Los hombres por su lado no presentan tanta variación etaria en la prevalencia del cuidado, pero sí se observa en ellos una evolución según la cual el condón pierde algo de importancia como método de cuidado primario y los métodos de cuidado "femeninos” (píldora y DIU) ganan espacio.

- Los niveles de cuidado en la última relación son preocupantemente bajos, en especial en la población en edad escolar (aunque también entre los mayores). Más de un tercio de los escolares

\footnotetext{
${ }^{34}$ En ese sentido, la estrategia óptima desde todo punto de vista consiste en el uso de un método hormonal de prevención del embarazo y también el condón (para evitar las ETS).

${ }^{35}$ Llama la atención la diferencia entre hombres y mujeres activos entre los jóvenes de 15 y 16 años. ¿Con quién tienen relaciones esos jóvenes? Puede ser que a edades más tempranas, los hombres tengan más incentivo a "alardear” de una relación sexual mientras las mujeres tiendan más al ocultamiento. Esto estaría sesgando los resultados de la tabla y mostraría una diferencia que no es real. Pero por otro lado lo que puede estar ocurriendo también es que a esas edades las mujeres que son activas tuviesen, en un determinado período, más parejas sexuales diferentes que los hombres que ya se han iniciado, y que a su vez los hombres recurran con mayor frecuencia a parejas mayores o prostitutas.
} 
que han tenido relaciones sexuales no se cuida. Casi un cuarto de los jóvenes de 19 años y más tampoco han tomado precauciones.

A continuación estudiaremos el comportamiento de los jóvenes en su primera relación sexual. Para ello reportamos en la Tabla $\mathrm{N}^{\circ} 4$ la prevalencia del uso de métodos de prevención en la primera relación, según la edad que el joven reporta haber tenido en esa ocasión ${ }^{36}$.

La Tabla $\mathrm{N}^{\circ} 4$ nos muestra cómo la edad en la cual se tiene la primera relación es muy determinante del nivel de protección utilizado en esa ocasión. Este efecto es especialmente marcado en las mujeres. En los hombres, a pesar de que los que se inician antes de los 15 años se cuidan bastante menos que los mayores en su primera relación, la prevalencia del cuidado en la primera relación no varía significativamente después de los 15 años. En general, el nivel de cuidado en la primera relación es preocupantemente bajo, sobre todo en jóvenes que comenzaron su actividad sexual durante la etapa escolar. Más de la mitad de las mujeres en este tramo etario no se cuidó en su primer encuentro. Las cifras son similares para los hombres. Todo esto implica que el peligro de embarazo y de ETS en este grupo es muy alto. De hecho, si miramos sólo a aquellos que comienzan su actividad sexual antes de los 18 nos damos cuenta de que su historial de fertilidad es bastante cuantioso. La Tabla $\mathrm{N}^{\circ} 5$ recoge la fertilidad de estos jóvenes. Las cifras son sorprendentes: casi la mitad de las jóvenes de 17 y 18 años que comenzaron su vida sexual antes de los 18 ya son madres.

$\begin{array}{lll}12 \text { a } 14 & 37,50 & 45,24 \\ 15 \text { a } 17 & 59,46 & 46,64 \\ 18 \text { a } 20 & 62,97 & 66,76 \\ 21 \text { a } 23 & 58,14 & 80,87 \\ & & \\ \text { Total } & 56,19 & 54,67\end{array}$

${ }^{36}$ No se reportan datos de quienes comenzaron su actividad sexual antes de los 12 años debido al pequeño tamaño de esa muestra (3 mujeres y 11 hombres). 
Tiene uno o más hijos (\% del grupo etario)*

Edad actual

Hombres

Mujeres

$15-16$

$17-18$

19-20

21-23

Total
0

12,35

10,28

22,18

12,88
20,36

48,32

67,45

84,54

53,81

* Esta tabla se confeccionó usando la muestra de menores de 24 años, pero esta vez incluyendo a aquellos que viven en pareja o desean embarazarse. Esto porque el nacimiento de un hijo podría inducir a los jóvenes a vivir en pareja (sacándolos de nuestro grupo objetivo de análisis). Sin embargo tenemos que considerar que esa decisión (de convivencia) podría haber surgido como consecuencia de una conducta riesgosa previa.

Dos tercios de las jóvenes de 19 y 20 años que comenzaron su vida sexual antes de los 18 lo son, y esta cifra sube a cerca del 85\% para las jóvenes de 21 a 23 años que tuvieron un inicio precoz de su sexualidad. El caso de los hombres es llamativo. Ellos reportan una fertilidad muy inferior a la de las mujeres. Esto puede deberse a que éstas tienen parejas que son en general bastante mayores que ellas. Sin embargo, la gran diferencia en las cifras lleva a suponer que muchos padres jóvenes no conocen (o no reconocen) su estatus.

La Tabla $\mathrm{N}^{\circ} 6$ presenta los datos de las tablas anteriores disgregados según nivel socioeconómico y sexo del joven. Esta tabla, al igual que las previas (con la excepción de la Tabla $\mathrm{N}^{\circ}$ 5), sólo analiza los datos de quienes no viven en pareja ni están buscando un embarazo.

Como podemos ver, las diferencias entre estratos socioeconómicos, en lo que se refiere a iniciación sexual, no son demasiado grandes, aunque existen. En cuando a actividad sexual, la principal diferencia se nota en el estrato $\mathrm{ABC} 1$, que muestra un menor número de jóvenes sexualmente activos. El grupo con más actividad sexual es el de jóvenes de nivel socioeconómico medio (C2). Por otro lado, la edad de la primera relación aumentaría con el nivel socioeconómico de los hombres jóvenes, aunque las diferencias en promedio no son demasiado grandes. Por otro lado, las mujeres jóvenes del grupo E son las más precoces, seguidas por el D y a continuación los grupos ABC1, C2 y 
TABLA N ${ }^{\circ}$ 6: $\quad$ DIFERENCIAS EN INICIACIÓN SEXUAL SEGÚN ESTRATO SOCIOECONÓMICO (\%)

\begin{tabular}{|c|c|c|c|c|}
\hline & \multicolumn{2}{|c|}{ Sexualmente activos } & \multicolumn{2}{|c|}{ Edad primera relación (años)* } \\
\hline & Hombre & Mujer & Hombre & Mujer \\
\hline ABC1 & 56,53 & 44,58 & 16,597 & 17,029 \\
\hline $\mathrm{C} 2$ & 64,60 & 54,36 & 16,436 & 17,126 \\
\hline C3 & 64,79 & 47,64 & 16,058 & 17,028 \\
\hline D & 56,74 & 50,84 & 15,899 & 16,701 \\
\hline E & 60,95 & 48,48 & 15,848 & 16,450 \\
\hline Total & 61,28 & 49,61 & 16,110 & 16,889 \\
\hline
\end{tabular}

* La estimación se hace sobre la base de los sexualmente activos.

C3, que son relativamente parecidos entre sí en este aspecto ${ }^{37}$. A continuación la Tabla $\mathrm{N}^{\circ} 7$ muestra el nivel de precauciones que toma la población de jóvenes activos sexualmente según su estrato socioeconómico.

La Tabla $\mathrm{N}^{\circ} 7$ nos muestra que la prevalencia del uso de métodos de prevención de embarazo y/o ETS varía, esta vez de manera importante, con el estrato socioeconómico al que pertenezca el joven. Mientras menos de un tercio de las mujeres del estrato E se cuidó en su primera relación, dos tercios de ellas lo hicieron en los estratos más altos (ABC1 y C2). Lo mismo ocurre con los hombres, que llegan a un nivel de cuidado del 80,4\% en el estrato ABC1, cuando en los estratos más bajos ( $\mathrm{D}$ y E) la prevalencia del uso de métodos de prevención durante la primera relación sexual apenas excede el 45\%. Lo mismo ocurre cuando vemos la conducta reciente, que de alguna manera se podría aproximar a la conducta "permanente" de los jóvenes. Mientras 9 de cada 10 jóvenes del estrato $\mathrm{ABC} 1$ se cuidaron en su última relación sexual, según se desciende de estrato la prevalencia del cuidado cae hasta llegar al estrato E donde casi la mitad de los jóvenes tiene

${ }^{37}$ Se podría argumentar que al excluir a los que viven en pareja y buscan embarazarse estamos ocultando una diferencia mayor entre estratos socioeconómicos respecto de la proporción de iniciados y la edad de iniciación. El argumento sería que en los estratos más bajos habría más parejas conviviendo y más mujeres en busca de embarazarse. Sin embargo, al replicar la Tabla $\mathrm{N}^{\circ} 6$ para el grupo extenso de jóvenes (incluyendo a quienes conviven y/o buscan embarazarse) seguimos encontrando cifras que no difieren mucho según nivel socioeconómico. 
TABLA N N $^{\circ}$ DIFERENCIAS EN PREVENCIÓN SEGÚN ESTRATO SOCIOECONÓMICO

\begin{tabular}{lcccc}
\hline & $\begin{array}{c}\text { Cuidado en la primera relación (\%)* } \\
\text { Hombre }\end{array}$ & Mujer & Cuidado en la última relación (\%)* \\
Hombre & Mujer \\
\hline ABC1 & 80,44 & 66,61 & 87,86 & 93,67 \\
C2 & 61,03 & 66,08 & 79,51 & 89,11 \\
C3 & 58,56 & 61,41 & 75,99 & 76,46 \\
D & 45,87 & 45,28 & 64,42 & 69,29 \\
E & 45,14 & 30,09 & 53,37 & 55,61 \\
& & & & 76,13 \\
Total & 56,17 & 54,7 & 72,56 & 76 \\
\hline
\end{tabular}

* La estimación se hace sobre la base de los sexualmente activos.

sexo desprotegido. Esto nos puede estar reflejando dos realidades: o los jóvenes más desaventajados no quieren o no saben de la relevancia de cuidarse, o éstos no tienen el adecuado acceso a los métodos de control de natalidad. Es muy difícil establecer cuál es la verdadera razón de este comportamiento, ya que la pregunta de la encuesta que busca dilucidar por qué estos jóvenes no se cuidaron tiene respuestas bastante desperdigadas con una fracción relevante que no respondió y una gran dispersión en las respuestas. Sin embargo, el patrón de respuestas sugiere que, aun no habiendo ninguna razón preponderante que lleve a los jóvenes a no cuidarse, los que aducen razones asociadas a preferir no usar protección, o quienes responden alternativas asociadas a la falta de planeación de sus encuentros sexuales, son muchos más que quienes aducen algún tipo de dificultad para conseguir algún método de prevención debido a su costo o a la ausencia del servicio en los consultorios, incluso en las clases más desposeídas.

Esto nos lleva a la Tabla $\mathrm{N}^{\circ}$ 8, que presenta el número de mujeres que han experimentado embarazos no deseados ${ }^{38}$ según nivel socioeconómico.

La Tabla $\mathrm{N}^{\circ} 8$ nos muestra una realidad bastante asombrosa: en el nivel socioeconómico E, sin importar la muestra considerada, prácticamente la mitad de las mujeres de entre 15 y 23 años ha tenido un embarazo no deseado. Los niveles socioeconómicos superiores muestran un paulatino declive en la prevalencia de estos embarazos, en línea con la evidencia de la Tabla $\mathrm{N}^{\circ} 7$, que muestra cómo los niveles más

${ }^{38}$ Esta tabla se basa en un ítem de la encuesta que pregunta directamente a las encuestadas si han tenido algún embarazo no deseado. 
acomodados son también los que previenen de mejor manera estos eventos. Existen quienes argumentan que en condiciones de pobreza, en muchas ocasiones el embarazo adolescente es un fenómeno deseado. Es muy posible que tal aseveración sea por lo menos parcialmente cierta y estos datos no nos permiten testearla ${ }^{39}$. Sin embargo, las estadísticas de la Tabla $\mathrm{N}^{0} 8$ sugieren que los sectores más desposeídos también tienen una mayor incidencia de embarazos no deseados. Es muy difícil extraer a partir de los datos de la encuesta cuáles de estos embarazos culminó en un nacimiento o en un aborto ya sea espontáneo o inducido. La pregunta no está directamente formulada, y el cruce entre existencia de algún embarazo no deseado y la presencia de hijos no es demasiado informativo ${ }^{40}$. Sin embargo, los datos de la NO DESEADO

\begin{tabular}{lll}
\hline ABC1 & 11,82 & \\
C2 & 27,05 & 12,65 \\
C3 & 31,01 & 19,75 \\
D & 42,85 & 23,37 \\
E & 46,65 & 32,16 \\
& & 46,22 \\
Total & 34,62 & 26,54
\end{tabular}

* Es decir, la muestra que se ha usado normalmente para los análisis a lo largo del artículo. Sólo activas sexualmente.

${ }^{39}$ Sólo tenemos información asociada al deseo "actual” de las jóvenes de tener un hijo (y esas jóvenes las excluimos de la base de cálculo). Sin embargo no sabemos cuántos de los hijos de cada joven han sido deseados y cuántos no, ya que la pregunta en cuestión se refiere a "embarazos" y no a "hijos".

${ }^{40}$ No es posible extraer de los datos cuántos de los embarazos no deseados llegaron a término. El número de hijos no es indicador, ya que éstos pueden haber sido fruto de otro embarazo que sí fue deseado. Sin embargo algo debería extraerse de la cifra que indica el número de jóvenes sin hijos que han vivido un embarazo no deseado (que por ende no llegó a término). Sin embargo la cifra, 8,15\%, es muy baja como para hacer cualquier especulación sobre ocurrencia o prevalencia de abortos inducidos. Entre las mujeres que saben que están en embarazo, la tasa de aborto espontáneo es alrededor del 15 al 20\% (ver por ejemplo http://www.nlm.nih.gov/medlineplus/spanish/ency/article/ 001488.htm). Puede ser que las jóvenes se den cuenta de sus embarazos bastante tardíamente, cuando el riesgo de pérdida ha disminuido sustancialmente. Por otro lado, también es posible que muchas jóvenes reporten menos embarazos que los que realmente les ocurren, en especial cuando éstos no llegan a término. 
Sexta Encuesta realizada en 2009, que incluye directamente una pregunta sobre aborto, indicarían de manera general (para todos los jóvenes de 15 a 29 años) que el 6,7\% de quienes han tenido un embarazo no planificado se ha realizado un aborto ${ }^{41}$.

\section{Determinantes de la actividad sexual y de la efectiva prevención del embarazo}

A continuación se presenta un estudio econométrico en el que se busca avanzar en el proceso de determinar cuáles son los predictores principales de la actividad sexual de los jóvenes y de su decisión de cuidarse o no. Un estudio en esta misma línea para Estados Unidos es el de Levine (2001), cuyo objetivo era intentar establecer los determinantes del comportamiento sexual juvenil y estimar hasta qué punto estos jóvenes respondían a los "precios" asociados a sus conductas a través del estudio de cambios en las políticas de bienestar (orientadas a la maternidad adolescente) en ese país.

En nuestro caso estimaremos un modelo de dos etapas: en la primera se modela la decisión de iniciar la actividad sexual, mientras que en la segunda se investiga la decisión de cuidarse desde que la actividad sexual fue iniciada.

Como los jóvenes que han iniciado su actividad sexual no son una selección aleatoria de la totalidad de jóvenes en el país, corregimos por un posible sesgo de selección aplicando los métodos de Heckman. En especial en este caso se estima un probit con corrección por selección de Heckman ${ }^{42}$. En pocas palabras, este modelo lo que hace es tomar en cuenta el hecho de que no podemos observar el comportamiento sexual (en lo que se refiere a prevención del embarazo) de todos los jóvenes, ya que algunos de ellos no se han iniciado aún. El grupo de los que sí comenzaron su actividad no es representativo de la población de jóvenes, pero sin embargo es el único que podemos observar, ya sea que se cuiden o no. Heckman desarrolla un modelo en el que se corrige

${ }^{41}$ Lamentablemente aún no contamos con la base de datos de la mencionada encuesta, por lo que debemos basarnos en el reporte de resultados principales. Dado que la encuesta es cara a cara, y la pregunta se refiere a una acción ilegal, es probable que los niveles de aborto hayan sido subreportados en la encuesta.

${ }^{42}$ Este modelo se estima mediante el comando heckprob, en STATA, que utiliza el método de máxima verosimilitud. 
por las distorsiones que esta no aleatoriedad traería al modelo. Para ello se modela la selección (es decir el hecho de que el joven haya o no comenzado su actividad sexual) como un probit auxiliar (aunque no por ello menos interesante para el análisis) y los resultados de esa modelación se incluyen en la ecuación que busca explicar el comportamiento preventivo de los jóvenes ${ }^{43}$. En nuestro caso, la variable dependiente principal es el cuidado en la última relación sexual.

En este tipo de modelos es recomendable que en la etapa de selección (en este caso, la decisión de comenzar la actividad sexual) se incluyan variables independientes que estén ausentes en la etapa posterior (que en nuestro caso corresponde a la decisión de cuidarse). Estas variables de exclusión deben tener sustento teórico y empírico. En nuestro caso decidimos usar como variable de exclusión una referida a la personalidad de los jóvenes (la variable binaria "tranquilo”). En general es esperable que jóvenes más tranquilos y que salen de fiesta con menor frecuencia tengan menos probabilidades de practicar una sexualidad activa debido a que se les darán menos oportunidades de entablar estas relaciones. Sin embargo esta característica de personalidad no debiera incidir en la probabilidad de que el joven tome las precauciones correspondientes al tener una relación. El documento de trabajo asociado a este artículo (Dussaillant, 2010) presenta una prueba empírica alternativa que refuerza la evidencia de que la variable "tranquilo" sería una buena variable de exculsión ${ }^{44}$.

El modelo se estima para la población joven total (15 a 23 años inclusive) y también separada por sexo. Como se comentó con anterioridad, se excluyen de la muestra a aquellos jóvenes que reportan estar buscando un embarazo (para ellos no cuidarse no es una actitud riesgosa) y a aquellos que viven con su pareja, ya sea en un matrimonio o en relación de convivencia. Como ya se comentó, los matrimonios y convivencias son relaciones relativamente estables donde los jóvenes ya

${ }^{43}$ El desarrollo analítico de los modelos de selección de Heckman se encuentra en variados textos de econometría, como por ejemplo Maddala (1983). El modelo aquí utilizado es levemente diferente, ya que la ecuación principal es un probit (y no un modelo con variable dependiente continua, como en el modelo original de Heckman). El probit con selección de Heckman está descrito en detalle en Van de Ven y Van Praag (1981).

${ }^{44}$ La prueba en cuestión es sólo evidencia parcial de la validez de la variable. Consistió en incluir la variable "tranquilo" en la estimación (excluyendo en ese caso otras variables que en la estimación original aparecían como no significativas y que teóricamente también tenían potencial de variables de exclusión). La prueba muestra que "tranquilo" no tiene un efecto significativo en la predicción de la toma de precauciones frente a una relación sexual. 
han tomado la responsabilidad financiera de sus vidas. Los jóvenes de este grupo se diferencian de aquellos que no conviven en que para los primeros la dimensión del riesgo de no cuidarse está bastante más acotada que para los últimos. En ese sentido corresponde tratarlos como grupos diferentes.

\section{Variables dependientes}

Como ya explicamos, el modelo tiene dos variables dependientes. La variable de selección es una variable binaria que indica si el o la joven ha iniciado su actividad sexual. Un(a) joven que ha tenido en su vida al menos una relación sexual con penetración es considerado(a) como iniciado(a). La variable dependiente principal tiene que ver con la prevención del embarazo, ya que indica si el o la joven se cuidó durante su última relación sexual. Por "cuidarse" nos referimos al uso de cualquier método de control de la natalidad, incluyendo anticonceptivos, dispositivo intrauterino, condón, inyectables, diafragma, coito interrumpido y métodos naturales entre otros. Por lo tanto, hay que tener presente que para los efectos de este análisis una persona que "se cuida” puede estar en riesgo de enfermedades de transmisión sexual (ETS) o incluso de embarazarse (al usar un método poco efectivo o al usarlo de manera inapropiada). Sin embargo, como se observó en la Tabla $N^{0} 3$, más de la mitad de quienes se cuidan lo hacen mediante el condón (que también los protege de las ETS) y muy pocos practican el coito interrumpido o recurren a los métodos naturales, que son los menos efectivos en la prevención del embarazo ${ }^{45}$.

\section{Variables independientes individuales}

La Encuesta Nacional de la Juventud tiene una gran cantidad de preguntas que permiten conocer el contexto familiar y social de cada joven encuestado, sus creencias, personalidad, preferencias, situación laboral y expectativas, entre otras. Muchas de estas variables podrían, desde un punto de vista teórico, afectar el comportamiento sexual de los jóvenes. En esta sección expondremos las variables utilizadas en la

45 En la Tabla $\mathrm{N}^{\circ} 3$ estos métodos conforman la categoría “otros”, junto con métodos inyectables y diafragma/espermicida. 
estimación. Dussaillant (2010) entrega una explicación más detallada de la construcción de cada una de estas variables.

Descriptivos básicos: Éstos incluyen el sexo, la edad y la edad del cuadrado.

Nivel socioeconómico: se generan indicadores para el nivel socioeconómico de los jóvenes. Los grupos son los tradicionales ${ }^{46} \mathrm{ABC} 1$, C2, C3, D y E.

Relación de pareja: se generan indicadores que especifican si el o la joven están solos (sin pareja), “andan” con alguien, tienen una relación de pololeo o están de novios. Recordemos que los convivientes o casados fueron excluidos de nuestra muestra.

Variables asociadas a la vida sexual: estas variables no se incluyen en la ecuación de selección ya que sólo están disponibles en la base de datos para los jóvenes que ya comenzaron su vida sexual. Se incluyen preferencias sexuales por personas del mismo sexo y años de experiencia sexual.

Personalidad: incluimos dentro de los predictores potenciales "trabajador” (que podría asociarse a responsable), “desordenado”, "consumista" (que podría asociarse a alguien exitista que busca el goce inmediato), "solitario", "tranquilo", "bueno para el carrete”, "sociable”47, "práctico” y "realista”.

Cultura sexual: un indicador especifica si el o la joven reportó haber recibido educación sexual en su colegio. Otras dos variables indican sus conocimientos respecto de la transmisión y la prevención del sida. Aunque estas preguntas se refieren al conocimiento particular de los jóvenes respecto del sida y no de su cultura en prevención del embarazo, a falta de datos de ese tipo usamos estos indicadores como proxys para la cultura sexual del joven.

Valores: la ENJ tiene una pregunta que pide al joven establecer su nivel de acuerdo con el divorcio, el matrimonio entre personas del mismo sexo, legalización de la marihuana, uso de la píldora del día

${ }^{46}$ El Instituto Nacional de la Juventud genera esos datos usando el modelo matriz de clasificación ESOMAR, en base a las variables de nivel educacional y ocupación de la persona que aporta el principal ingreso en el hogar, así como una batería complementaria de posesión de bienes. (INJUV, 2008.)

${ }^{47}$ Se podría argumentar que algunas de estas variables tiene potencial de endogeneidad. En especial nos referimos a las variables "sociable" y "bueno para el carrete". Puede argumentarse que ser "sociable" o "bueno para el carrete" no sólo es causa del comportamiento sexual sino también consecuencia. 
después, el matrimonio como institución para toda la vida, la eutanasia y el aborto terapéutico.

El alto nivel de colinearidad en las respuestas nos llevó a la necesidad de resumirlas en dos indicadores de "valores liberales"48. Estos factores se estimaron mediante el método de componentes principales. Los coeficientes asignados a cada valor se presentan en el Apéndice. El primer factor, denominado "valores liberales generales" describe el nivel de "liberalidad" valórica del joven, en términos bastantes generales. Por otro lado, el segundo factor, "valores liberales particulares" 49 tiene características más especiales. Quienes tienen una visión muy conservadora del matrimonio como una institución específicamente heterosexual que debe durar toda la vida y donde el divorcio tiene poca cabida, tendrán un alto puntaje en este índice. También tendrán más puntaje quienes están en desacuerdo con iniciativas más rupturistas como la legalización de la marihuana. Por otro lado, este índice valora positivamente algunas posiciones liberales menos controvertidas entre los jóvenes como la eutanasia o el aborto en caso de peligro de muerte de la madre ${ }^{50}$.

Relaciones de familia: en primer lugar dos variables especifican la nota promedio que el o la joven asigna a su madre y padre en términos de la calidad de comunicación con el hijo, demostración de afecto y cariño hacia él, comprensión y apoyo a sus inquietudes y tiempo que pasa con éste. Para generar las últimas dos variables usamos una pregunta de la encuesta que se refiere a los problemas familiares ocurridos en los últimos tres meses en la familia de origen del joven. A partir de las respuestas a los siete problemas enumerados por la pregunta se generaron dos índices, estimados con el método de los componentes principales. Las ponderaciones asignadas a cada problema por cada índice se presentan en el Apéndice. El primer índice

${ }^{48}$ La denominación "liberal” aquí se refiere a valores que están asociados a responsabilidad individual (y por ende a una iniciación sexual más temprana pero probablemente con mayor cuidado y protección). No confundir la dicha acepción con la visión de alguien ligero, audaz e irresponsable.

${ }^{49}$ Podríamos haberlos llamado alternativamente "valores conservadores particulares".

${ }^{50}$ La encuesta en referencia muestra que legalización de la marihuana es la categoría menos aceptada por los jóvenes. Dussaillant (2010) presenta una descripción de las respuestas a cada una de las preguntas valóricas, y muestra que efectivamente la eutanasia y el aborto en caso de peligro de vida de la madre son categorías relativamente aceptadas por los jóvenes. 
(denominado malas relaciones en general) refleja el ambiente general en la familia de origen del joven. Por su parte, el segundo factor (denominado dificultades económicas y de comunicación) se asocia a la presencia de problemas que no están ligados al maltrato explícito pero que disminuyen la calidad de vida del joven.

Confianza y discriminación: dos de estas variables indican el nivel de confianza que el joven tiene con sus amigos y el gusto que siente al estar con ellos. Las variables de confianza no deben tomarse como indicador de un "efecto par", ya que no conocemos las características particulares de esos amigos en los que se confía. De hecho, es muy posible que para alguno de los individuos de la muestra el grupo de amigos en el que se confía actúe como factor protector mientras que en otro sea un factor de riesgo de comportamiento sexual desprotegido. Por otro lado, estas variables de confianza sí identifican al grupo de jóvenes que se sienten aislados socialmente (con valor cero en las variables recién mencionadas). La evidencia es bastante concluyente en predecir que los adolescentes más autocríticos, ansiosos, enojados, tristes, depresivos o culposos, junto con aquellos con problemas de inhibición social, sentimientos de inadecuación y sensibilidad extrema a la evaluación negativa, que en general evitan instancias sociales, tienen una mayor probabilidad de manifestar conductas riesgosas ${ }^{51}$. Respecto de la percepción de discriminación se generaron tres variables: la primera se refiere a percepción de discriminación por parte de los pares, que podría estar indicando que la persona no es socialmente aceptada y por ende está más bien aislada del medio social. También se incluye una variable de "discriminación por apariencia” que podría indicar que el joven tiene una apariencia poco atractiva según las normas del grupo o de la sociedad. Finalmente se incluye “discriminación por carabineros y/o figuras de autoridad”, que sospechamos podría indicarnos que el joven tiene un historial de más rebeldía que el promedio.

Religión: cuatro de estas variables indican si el joven es católico, cristiano no católico, si tiene otra religión o si no tiene religión. La quinta y sexta variables indican si el joven asiste a servicios religiosos con frecuencia semanal o mensual. Las variables se construyen de manera incremental, tomando en cuenta que una persona con asistencia semanal también asiste a los servicios de manera mensual.

${ }^{51}$ Ver Reyna y Farley (2006), que se refieren a los trabajos que han llegados a estas 
Trabajo: se agregan indicadores de si el joven estudia, si trabaja y si busca trabajo. Se da una discusión que argumenta que estas variables son endógenas al comportamiento sexual de los jóvenes. Lo que sucede es que hay la posibilidad de causalidad inversa, es decir que el estatus laboral del joven se vea afectado por su conducta sexual (especialmente si surge un embarazo). Es por ello que estas variables serán excluidas del modelo principal que aquí reportamos. Sin embargo, estimamos un modelo alternativo en el que se incluyeron estas variables y es a partir de éste que reportamos los efectos asociados a estas variables. La interpretación de estos efectos, sin embargo, deberá realizarse con cautela.

\section{Variables contextuales (con base comunal)}

Entre las variables explicativas evaluadas se incluyen variables relacionadas con el entorno comunal de los jóvenes. En especial se incluye una variable que tiene que ver con el desempleo comunal de hombres de entre 30 y 50 años inclusive. Esta variable, que se obtiene a partir de la Encuesta Casen 2006, sirve como indicador de la calidad del mercado laboral en la zona donde habita el joven. Por el hecho de referirse a hombres que ya no pertenecen al rango de edad en estudio, este indicador podría considerarse como exógeno, a diferencia de las variables de estatus laboral individual, como se discutió más arriba.

Otras variables comunales que se utilizaron tienen que ver con el nivel de drogas en la comuna donde habita el joven. Para ello se utilizó la Encuesta Nacional de Drogas en Población General, del Conace de 2006. A partir de esta encuesta se generaron indicadores de incidencia del consumo (por parte de la juventud) de alcohol y marihuana, además de la percepción de los jóvenes sobre la existencia de tráfico en su barrio. Estos índices se construyeron considerando sólo a la población menor de 30 años de cada comuna para que de esa manera representen una medida del nivel de drogadicción comunal juvenil. En el Apéndice se explica en detalle cómo se construyeron estos indicadores.

Hubiera sido interesante investigar la correlación entre la actitud sexual del joven y su propio nivel de consumo de estas sustancias. Lamentablemente la Encuesta Nacional de la Juventud no recoge información sobre uso de drogas en los jóvenes. Por otro lado, el indicador comunal tiene la ventaja de ser un descriptor del ambiente del barrio en 
el que vive el joven. En ese sentido, los coeficientes que obtenemos a partir de estas variables nos entregan un indicio del efecto que el contexto que rodea al joven tiene en su comportamiento sexual.

\section{Estadísticas descriptivas}

A continuación se entrega una tabla con las estadísticas descriptivas asociadas a cada una de las variables recién descritas. Se entrega información para la población total y para mujeres y hombres por separado.

TABLA N ${ }^{\circ}$ 9: $\quad$ ESTADÍSTICAS DESCRIPTIVAS

\begin{tabular}{|c|c|c|c|c|c|c|c|c|}
\hline & & dos & Muj & jeres & Hom & nbres & & \\
\hline & Promedio & $\begin{array}{l}\text { Desv. } \\
\text { est. }\end{array}$ & Promedio & $\begin{array}{l}\text { Desv. } \\
\text { est. }\end{array}$ & Promedio & $\begin{array}{l}\text { Desv. } \\
\text { est. }\end{array}$ & Mín. & Máx. \\
\hline Variables dependientes & & & & & & & & \\
\hline inició su actividad sexual & 0,568 & 0,495 & 0,511 & 0,500 & 0,622 & 0,485 & 0 & 1 \\
\hline se cuidó en la última relación & n 0,756 & 0,429 & 0,765 & 0,424 & 0,750 & 0,433 & 0 & 1 \\
\hline $\begin{array}{l}\text { Descriptivos básicos } \\
\text { muier }\end{array}$ & 0.486 & 0,500 & & & & & 0 & 1 \\
\hline edad & 18,599 & 2,587 & 18,572 & 2,586 & 18,624 & 2,587 & 15 & 23 \\
\hline edad $^{2}$ & 352,608 & 97,386 & 351,611 & 97,267 & 353,552 & 97,489 & 225 & 529 \\
\hline Nivel socioeconómico & & & & & & & & \\
\hline ABC1 & 0,109 & 0,311 & 0,109 & 0,311 & 0,109 & 0,311 & 0 & 1 \\
\hline C2 & 0,191 & 0,393 & 0,185 & 0,388 & 0,196 & 0,397 & 0 & 1 \\
\hline C3 & 0,362 & 0,480 & 0,354 & 0,478 & 0,369 & 0,483 & 0 & 1 \\
\hline $\mathrm{D}$ & 0,283 & 0,450 & 0,295 & 0,456 & 0,271 & 0,445 & 0 & 1 \\
\hline $\mathrm{E}$ & 0,057 & 0,231 & 0,059 & 0,235 & 0,055 & 0,227 & 0 & 1 \\
\hline Relación de pareja & & & & & & & & \\
\hline de novio & 0,017 & 0,130 & 0,026 & 0,160 & 0,009 & 0,093 & 0 & 1 \\
\hline pololeo & 0,347 & 0,476 & 0,394 & 0,489 & 0,302 & 0,459 & 0 & 1 \\
\hline ando & 0,113 & 0,316 & 0,086 & 0,281 & 0,137 & 0,344 & 0 & 1 \\
\hline solo & 0,523 & 0,499 & 0,493 & 0,500 & 0,552 & 0,497 & 0 & 1 \\
\hline Vida sexual & & & & & & & & \\
\hline años desde primera relación & 3,309 & 2,289 & 2,980 & 2,037 & 3,564 & 2,437 & 0 & 12 \\
\hline homosexual o bisexual & 0,060 & 0,237 & 0,047 & 0,212 & 0,070 & 0,254 & 0 & 1 \\
\hline Personalidad & & & & & & & & \\
\hline carretero & 0,150 & 0,357 & 0,115 & 0,320 & 0,182 & 0,386 & 0 & 1 \\
\hline sociable & 0,309 & 0,462 & 0,330 & 0,470 & 0,290 & 0,454 & 0 & 1 \\
\hline solitario & 0,083 & 0,275 & 0,083 & 0,276 & 0,082 & 0,274 & 0 & 1 \\
\hline tranquilo & 0,260 & 0,439 & 0,257 & 0,437 & 0,263 & 0,440 & 0 & 1 \\
\hline desordenado & 0,191 & 0,393 & 0,152 & 0,359 & 0,228 & 0,419 & 0 & 1 \\
\hline
\end{tabular}




\begin{tabular}{|c|c|c|c|c|c|c|c|c|}
\hline consumista & 0,058 & 0,233 & 0,068 & 0,252 & 0,048 & 0,214 & 0 & 1 \\
\hline trabajador & 0,280 & 0,449 & 0,272 & 0,445 & 0,288 & 0,453 & 0 & 1 \\
\hline práctico & 0,128 & 0,334 & 0,112 & 0,315 & 0,143 & 0,350 & 0 & \\
\hline realista & 0,237 & 0,425 & 0,231 & 0,421 & 0,242 & 0,429 & 0 & \\
\hline \multicolumn{9}{|l|}{ Cultura sexual } \\
\hline recibió educación sexual & 0,444 & 0,497 & 0,463 & 0,499 & 0,425 & 0,494 & 0 & \\
\hline culto prevención VIH & 0,203 & 0,402 & 0,202 & 0,402 & 0,204 & 0,403 & 0 & \\
\hline inculto transmisión VIH & 0,148 & 0,356 & 0,142 & 0,349 & 0,155 & 0,362 & 0 & \\
\hline \multicolumn{9}{|l|}{ Valores } \\
\hline valores liberales generales & $-0,040$ & 0,984 & $-0,100$ & 0,976 & 0,016 & 0,987 & $-2,920$ & 2,378 \\
\hline valores liberales particulares & $-0,033$ & 0,986 & $-0,092$ & 1,009 & 0,023 & 0,961 & $-3,618$ & 3,308 \\
\hline \multicolumn{9}{|l|}{ Ambiente familia de origen } \\
\hline nota madre & 5,858 & 1,454 & 5,852 & 1,407 & 5,864 & 1,497 & 0 & \\
\hline ota padre & 4,659 & 2,142 & 4,524 & 2,186 & 4,788 & 2,091 & 0 & \\
\hline malas relaciones general & 0,030 & 0,986 & 0,110 & 1,035 & $-0,046$ & 0,932 & $-0,975$ & 3,467 \\
\hline $\begin{array}{l}\text { dificultades econom. } \\
\text { y de comunic. }\end{array}$ & 0,010 & 1,001 & 0,036 & 0,998 & $-0,013$ & 1,003 & $-4,244$ & 1,708 \\
\hline \multicolumn{9}{|l|}{$\begin{array}{l}\text { Confianza y percepción de } \\
\text { discriminación }\end{array}$} \\
\hline confianza amigos & 0,858 & 0,349 & 0,865 & 0,342 & 0,851 & 0,356 & 0 & \\
\hline gusto estar amigos & 0,963 & 0,190 & 0,962 & 0,191 & 0,963 & 0,189 & 0 & \\
\hline discriminación apariencia & 0,181 & 0,438 & 0,202 & 0,462 & 0,161 & 0,414 & 0 & \\
\hline discriminación pares & 0,046 & 0,210 & 0,049 & 0,215 & 0,044 & 0,204 & 0 & 1 \\
\hline $\begin{array}{l}\text { alscriminacion } \\
\text { o autoridad }\end{array}$ & 0,201 & 0,401 & 0,184 & 0,387 & 0,217 & 0,412 & 0 & 1 \\
\hline \multicolumn{9}{|l|}{ Religión } \\
\hline istencia semanal & 0,146 & 0,353 & 0,155 & 0,361 & 0,139 & 0,346 & 0 & 1 \\
\hline asistencia mensual & 0,214 & 0,410 & 0,239 & 0,426 & 0,191 & 0,393 & 0 & \\
\hline tólico & 0,575 & 0,494 & 0,621 & 0,485 & 0,532 & 0,499 & 0 & \\
\hline cristiano no católico & 0,152 & 0,359 & 0,161 & 0,367 & 0,143 & 0,350 & 0 & \\
\hline otra religión & 0,020 & 0,141 & 0,017 & 0,130 & 0,023 & 0,151 & 0 & . \\
\hline \multicolumn{9}{|l|}{ Estatus laboral } \\
\hline $\begin{array}{l}\text { estudia } \\
\text { trabaja }\end{array}$ & $\begin{array}{l}0,705 \\
0,196\end{array}$ & $\begin{array}{l}0,456 \\
0,397\end{array}$ & $\begin{array}{l}0,718 \\
0,159\end{array}$ & $\begin{array}{l}0,450 \\
0,366\end{array}$ & $\begin{array}{l}0,693 \\
0,232\end{array}$ & $\begin{array}{l}0,461 \\
0,422\end{array}$ & 0 & 1 \\
\hline busca & 0,231 & 0,422 & 0,232 & 0,422 & 0,230 & 0,421 & 0 & . \\
\hline \multicolumn{9}{|l|}{$\begin{array}{l}\text { Ambiente laboral comunal } \\
\text { desocupación comunal }\end{array}$} \\
\hline (hombres 30-50) & 0,041 & 0,022 & 0,041 & 0,022 & 0,041 & 0,022 & 0,004 & 0,091 \\
\hline \multicolumn{9}{|l|}{ Ambiente drogas comunal } \\
\hline problemas marihuana & 1,117 & 1,364 & 1,122 & 1,344 & 1,112 & 1,382 & 0 & 5,519 \\
\hline tráfico & 0,296 & 0,174 & 0,296 & 0,173 & 0,295 & 0,176 & 0 & 0,756 \\
\hline Total observaciones válidas & 2.951 & & 1.524 & & 1.427 & & & \\
\hline \multicolumn{9}{|l|}{ Total individuos luego de } \\
\hline aplicar expansión & 517.056 & & 786.311 & & 830.745 & & & \\
\hline
\end{tabular}

Nota: Se incluyó a los jóvenes de entre 15 y 24 años que no viven con su pareja ni desean embarazarse. Sólo se incluye aquellos jóvenes para los que hay datos de nivel de drogas comunal, según Encuesta General de Drogas de Conace. 


\section{Resultados de las regresiones}

La Tabla $N^{\circ} 10$ presenta los resultados detallados de las regresiones, tanto para la ecuación de selección (que, como ya explicamos, predice la iniciación sexual) como para la ecuación principal (que predice cuidado en la última relación). Sólo se presentan las estimaciones en forma de efectos marginales ${ }^{52}$. Las estimaciones de los coeficientes puntuales y los resultados completos para dos modelos alternativos al reportado aquí, que confirman la robustez de las estimaciones, se encuentran en Dussaillant (2010).

A pesar de que, como veremos más adelante, los comportamientos de mujeres y hombres son relativamente diferentes, decidimos reportar también una estimación que reúne a la población de ambos sexos, ya que el mayor tamaño muestral y la mayor varianza de los predictores permiten en algunos casos establecer significancias que están ausentes tanto del modelo particular para hombres como del modelo particular para mujeres. Además, un modelo que incluya a ambos sexos nos permite estimar de manera relativa, al agregar una variable indicadora "mujer", cuál es la diferencia entre el comportamiento de un hombre y el de una mujer cuando todo el resto se mantiene constante.

\section{Análisis de los resultados}

La mejor manera de proceder con este análisis es mirar detalladamente el efecto que los distintos conjuntos de variables tienen en las decisiones de los jóvenes. Por ende, realizaremos el análisis de esa manera. Los efectos marginales nos informan sobre el efecto que tiene el cambio en una unidad de una variable independiente en la probabilidad de iniciación o en la probabilidad de uso de protección en una relación sexual. El efecto se expresa en términos de puntos porcentuales de incremento o descenso en la probabilidad promedio, manteniendo todo el resto constante. Según la Tabla № 10, estas probabilidades promedio son, para el caso del cuidado en la última relación, de 73,9\%

52 Estos efectos se calculan en el valor promedio de las variables, y en el caso de variables binarias corresponden al cambio en la probabilidad cuando la variable independiente pasa de tener valor cero a tener valor uno. 
TABLA N ${ }^{\circ}$ 10: $\quad$ ESTIMACIÓN DEL MODELO: EFECTOS MARGINALES

\begin{tabular}{|c|c|c|c|c|c|c|}
\hline & $\begin{array}{r}\text { Ecuacic } \\
\text { (Variable } \\
\text { cuidado en la }\end{array}$ & $\begin{array}{l}\text { ón principal } \\
\text { dependiente: } \\
\text { a última relaci }\end{array}$ & & $\begin{array}{r}\text { Ecuac } \\
\text { (Varia } \\
\text { sexu }\end{array}$ & $\begin{array}{l}\text { ción de selecc } \\
\text { able dependie } \\
\text { almente activ }\end{array}$ & \\
\hline & Todos & Mujeres & Hombres & Todos & Mujeres & Hombres \\
\hline mujer & $\begin{array}{r}-0,00371 \\
(0,0352)\end{array}$ & & & $\begin{array}{r}-0,206^{* * *} \\
(0,0284)\end{array}$ & & \\
\hline edad & $\begin{array}{l}0,0238 \\
(0,120)\end{array}$ & $\begin{array}{r}-0,0158 \\
(0,175)\end{array}$ & $\begin{array}{r}0,119 \\
(0,168)\end{array}$ & $\begin{array}{r}0,420 * * * \\
(0,0933)\end{array}$ & $\begin{array}{r}0,480^{* * *} \\
(0,137)\end{array}$ & $\begin{array}{r}0,357 * * * \\
(0,127)\end{array}$ \\
\hline edad $^{2}$ & $\begin{array}{l}0,000323 \\
(0,00313)\end{array}$ & $\begin{array}{r}0,00176 \\
(0,00455)\end{array}$ & $\begin{array}{r}-0,00265 \\
(0,00440)\end{array}$ & $\begin{array}{r}-0,0078^{* * *} \\
(0,00247)\end{array}$ & $\begin{array}{r}-0,00915^{* *} \\
(0,00363)\end{array}$ & $\begin{array}{r}-0,00631 * \\
(0,00335)\end{array}$ \\
\hline Nivel & caren & I & & & & \\
\hline $\mathrm{C} 2$ & $\begin{array}{r}-0,0194 \\
(0,0827)\end{array}$ & $\begin{array}{r}0,01000 \\
(0,107)\end{array}$ & $\begin{array}{r}-0,0360 \\
(0,111)\end{array}$ & $\begin{array}{l}0,00614 \\
(0,0564)\end{array}$ & $\begin{array}{r}0,0217 \\
(0,0751)\end{array}$ & $\begin{array}{r}0,0330 \\
(0,0731)\end{array}$ \\
\hline C3 & $\begin{array}{r}-0,124 \\
(0,0784)\end{array}$ & $\begin{array}{c}-0,192^{*} \\
(0,108)\end{array}$ & $\begin{array}{r}-0,0778 \\
(0,103)\end{array}$ & $\begin{array}{r}0,0370 \\
(0,0509)\end{array}$ & $\begin{array}{r}0,0231 \\
(0,0664)\end{array}$ & $\begin{array}{r}0,0667 \\
(0,0662)\end{array}$ \\
\hline D & $\begin{array}{r}-0,196 * * \\
(0,0838)\end{array}$ & $\begin{array}{r}-0,230 * * \\
(0,116)\end{array}$ & $\begin{array}{r}-0,179 \\
(0,115)\end{array}$ & $\begin{array}{r}0,0694 \\
(0,0527)\end{array}$ & $\begin{array}{r}0,0832 \\
(0,0717)\end{array}$ & $\begin{array}{r}0,0689 \\
(0,0675)\end{array}$ \\
\hline E & $\begin{array}{r}-0,375^{* * *} \\
(0,102)\end{array}$ & $\begin{array}{r}-0,498 * * * \\
(0,140)\end{array}$ & $\begin{array}{r}-0,318^{* *} \\
(0,143)\end{array}$ & $\begin{array}{r}0,130 * \\
(0,0642)\end{array}$ & $\begin{array}{r}0,142 \\
(0,0974)\end{array}$ & $\begin{array}{r}0,131 \\
(0,0750)\end{array}$ \\
\hline Relaci & categoría omiti & ida: de novio) & & & & \\
\hline polole & $\begin{array}{r}0,0216 \\
(0,0877)\end{array}$ & $\begin{array}{r}-0,127 \\
(0,117)\end{array}$ & $\begin{array}{r}0,202 \\
(0,155)\end{array}$ & $\begin{array}{r}-0,0981 \\
(0,153)\end{array}$ & $\begin{array}{r}-0,153 \\
(0,184)\end{array}$ & $\begin{array}{l}0,0983 \\
(0,182)\end{array}$ \\
\hline ando & $\begin{array}{r}-0,178 \\
(0,122)\end{array}$ & $\begin{array}{r}-0,229 \\
(0,176)\end{array}$ & $\begin{array}{r}-0,0141 \\
(0,200)\end{array}$ & $\begin{array}{r}-0,440^{* * *} \\
(0,124)\end{array}$ & $\begin{array}{r}-0,445^{* * *} \\
(0,106)\end{array}$ & $\begin{array}{r}-0,254 \\
(0,224)\end{array}$ \\
\hline solo & $\begin{array}{r}-0,0847 \\
(0,0928)\end{array}$ & $\begin{array}{r}-0,177 \\
(0,121)\end{array}$ & $\begin{array}{l}0,0777 \\
(0,195)\end{array}$ & $\begin{array}{r}-0,479 * * * \\
(0,120)\end{array}$ & $\begin{array}{r}-0,562 * * * \\
(0,139)\end{array}$ & $\begin{array}{r}-0,248 \\
(0,177)\end{array}$ \\
\hline
\end{tabular}

Vida sexual años desde primera relación

$\begin{array}{ccc}-0,0164 * & -0,0186 & -0,00708 \\ & & \\ (0,0102) & (0,0143) & (0,0130) \\ -0,0836 & -0,218^{*} & -0,0101 \\ & & \\ (0,0749) & (0,125) & (0,0864)\end{array}$

homosexual

$(0,0749) \quad(0,125)$

Personalidad

carretero

$0,0125 \quad 0,0154 \quad 0,0116$

$0,124 * * *$

0,103

$0,168 * * *$

$(0,0398) \quad(0,0613)$

sociable

0,00556

$-0,0221$

$(0,0522)$

$(0,0407)$

$(0,0681)$

$(0,0422)$

solitario

$(0,0339)$

$-0,00493$

$0,107 * * *$

0,0661

$0,142 * * *$

$-0,00417 \quad-0,0810$

$0,0448)$

$(0,0307)$

$(0,0471)$

$(0,0368)$

$(0,0628) \quad(0,104)$

$(0,0771)$

0,0239

$-0,0962$

tranquilo

$-0,0757 * *$

$(0,0792)$

$(0,0714)$

desordenado

$-0,0184 \quad-0,0364$

$(0,0367)$

$-0,0256$

$-0,107 * *$

consumista

$\begin{array}{rr}-0,0437) & (0,0611) \\ -0,0786 & -0,174 *\end{array}$

0,0164

$-0,00660$

$(0,0532)$

$(0,0483)$

$(0,0545)$

$(0,0399)$

$-0,00299$

0,00297

$-0,110^{*}$

$(0,0459)$

$(0,0680) \quad(0,0958)$

$(0,0903)$

$(0,0610)$

$-0,0888$

$(0,0797)$

$-0,0738$

$(0,0930)$ 


$\begin{array}{lrrrrrr}\text { trabajador } & 0,0414 & 0,0457 & 0,0311 & 0,0169 & -0,0589 & 0,0789 * \\ \text { práctico } & (0,0373) & (0,0546) & (0,0502) & (0,0353) & (0,0514) & (0,0427) \\ & 0,0667 & 0,130 * & 0,0194 & 0,0287 & 0,141^{* *} & -0,0312 \\ \text { realista } & (0,0428) & (0,0509) & (0,0619) & (0,0438) & (0,0661) & (0,0560) \\ & -0,0175 & -0,0629 & 0,0290 & 0,0298 & 0,0408 & 0,0331 \\ & (0,0369) & (0,0532) & (0,0475) & (0,0338) & (0,0486) & (0,0443) \\ \text { Cultura sexual } & & & & & & \\ \text { recibió educación sexual } & 0,0776 * * & 0,0533 & 0,0976 * * & 0,0312 & 0,0584 & 0,0202 \\ & (0,0319) & (0,0447) & (0,0444) & (0,0290) & (0,0429) & (0,0380 \\ \text { inculto prevención VIH } & -0,133^{* * *} & -0,0748 & -0,182 * * * & -0,00748 & -0,00809 & 0,0111 \\ & (0,0432) & (0,0648) & (0,0609) & (0,0365) & (0,0512) & (0,0484) \\ \text { inculto transmisión VIH } & -0,0630 & -0,0872 & -0,0750 & 0,00812 & 0,0872 & -0,0745 \\ & (0,0472) & (0,0667) & (0,0666) & (0,0385) & (0,0538) & (0,0536)\end{array}$

Valores

valores liberales generales $\quad 0,0236$ $(0,0190)$

0,0247

0,0288

$0,0741 * * *$

$0,0919 * * * \quad 0,0555 * * *$

$(0,0282)$

$(0,0243)$

$(0,0164)$

$(0,0255)$

$(0,0201)$

valores liberales particulares 0,00694

$0,0352 *$

$-0,0297$

$-0,0212$

$-0,0223$

$-0,0166$

$(0,0155)$

$(0,0220)$

$(0,0209)$

$(0,0142)$

$(0,0209)$

$(0,0187)$

Ambiente familia de origen

nota madre

$-0,0109$

$-0,00886$

$-0,0130-0,0387 * * *$

$(0,0108)$

$(0,0150)$

nota_padre

0,00939

0,00897

$(0,0115)$

$-0,0516^{* * *}$

$-0,0289 * *$

$0,00819 \quad 0,000144$

$(0,0164)$

$(0,0137)$

$(0,0108)$

$(0,0105) \quad(0,00712)$

$-0,0197 * *$

$0,0183^{*}$

malas relaciones general $\quad-0,0209$

$-0,0234$

$-0,0217$

0,0329*

$(0,0100)$

$(0,00932)$

$(0,0243) \quad(0,0229) \quad(0,0173)$

dificultades económ. y $\quad 0,0336 * *$

$0,0458 * \quad 0,0249$

0,00566

0,0385

0,0281

$(0,0244) \quad(0,0230)$

de comunic.

$(0,0147)$

$(0,0217) \quad(0,0203) \quad(0,0135)$

$0,0406 * *$

$-0,0202$

$(0,0195)$

$(0,0179)$

Confianza y percepción de discriminación

\section{Religión (frecuencia)}

asistencia semanal

$\begin{array}{rr}-0,113 & -0,229 \\ (0,115) & (0,160) \\ 0,131^{*} & 0,140^{*} \\ (0,0641) & (0,0786)\end{array}$

\section{0,000486}

$-0,181^{* *}$

$-0,184 * *$

$-0,224 *$

$(0,145) \quad(0,0760)$

$0,0999 \quad-0,0978$

$(0,0954)$

$(0,0674)$

$-0,0918$

$(0,132)$

$-0,0962$

$(0,117)$

Religión (denominación omitida: sin religión)

$\begin{array}{lrr}\text { católica } & -0,0231 & -0,0589 \\ & (0,0387) & (0,0569) \\ \text { cristiana no católica } & -0,0751 & -0,107 \\ & (0,0667) & (0,0868) \\ \text { otra religión } & 0,0700 & -0,0116 \\ & (0,104) & (0,197)\end{array}$

$-0,00531$

$(0,0505)$

$-0,0622$

$(0,0917)$

0,130

$(0,0990)$

0,0415

$(0,0360)$

0,0386

$(0,0502)$

$-0,0365$

$(0,109)$

$\begin{array}{rr}0,0935 * & 0,000909 \\ (0,0562) & (0,0442) \\ 0,0857 & 0,0176 \\ (0,0780) & (0,0626) \\ -0,00877 & -0,0239 \\ (0,143) & (0,143)\end{array}$

(continúa) 


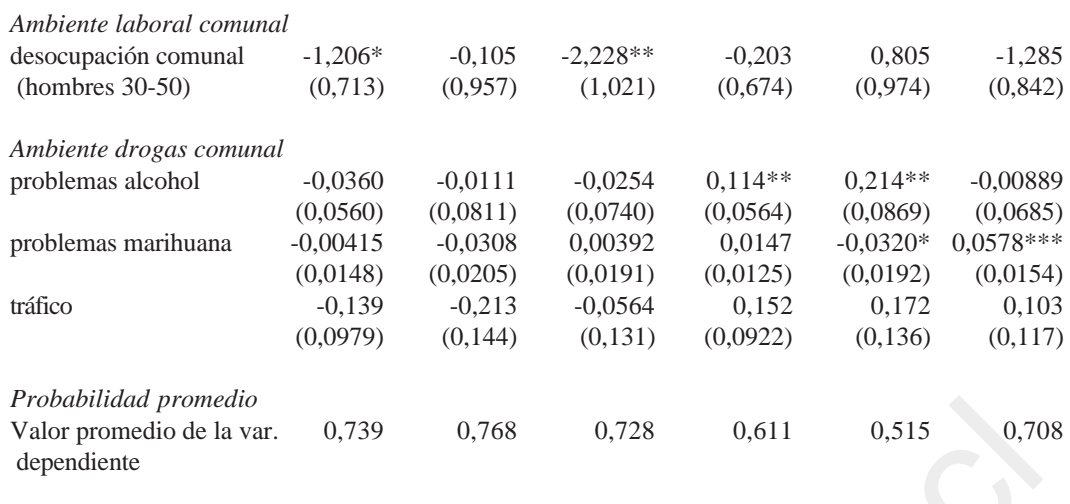

Errores estándares entre paréntesis ${ }^{*} \mathrm{p}<0,10, * * \mathrm{p}<0,05, * * * \mathrm{p}<0,01$.

para la muestra total, 76,8\% para mujeres y $72,8 \%$ para hombres $^{53}$. Respecto de la iniciación sexual las probabilidades promedio asociadas son de $61,1 \%$ (si es mujer, $51,5 \%$ y si es hombre, $70,8 \%$ ). Por "todo el resto constante" nos referimos a que al estudiar el efecto de una variable en particular estamos asumiendo que todo el resto de las variables independientes se mantiene en su valor promedio muestral (contenido en la Tabla $\mathrm{N}^{\circ}$ 9). A continuación se explicará, con un ejemplo, el significado exacto de las aseveraciones que haremos durante el análisis de los resultados de las estimaciones.

Al decir, por ejemplo, que un punto más en la nota de la madre disminuye la probabilidad de iniciación en 3,9 puntos porcentuales en la muestra total, 5,2 en las mujeres y 2,9 en hombres, tenemos que comparar esos efectos con las probabilidades promedio de iniciación reportadas en el párrafo anterior. Así, los jóvenes de 18,6 años (edad promedio en la muestra) que asignaron a su madre una nota que supera en un punto a la nota promedio ${ }^{54}$, tienen probabilidades de iniciación de $57,2 \%$ para la muestra total, $46,3 \%$ para mujeres y $67,9 \%$ en hom-

${ }^{53}$ Estos valores son los valores promedio para los casos que fueron finalmente utilizados para realizar las regresiones. No incluyen casos que se perdieron debido a falta de alguna información relevante. En especial se perdieron varios casos por falta de información sobre drogas en la comuna de residencia del joven. Por ello, los datos reportados difieren, aunque muy levemente, de los reportados en la Tabla $\mathrm{N}^{\circ} 2$.

${ }^{54}$ Esa nota promedio la podemos conocer mirando la Tabla $\mathrm{N}^{\circ} 9$ de descriptivos y corresponde a 5,9 tanto para la muestra total, como para mujeres o para hombres. 
bres $^{55}$. De la misma manera podemos inferir que quienes reportan una nota que es cuatro puntos inferior al promedio tienen probabilidades de iniciación de $76,7 \%$ en la muestra total, $72,3 \%$ en mujeres y $82,4 \%$ en hombres ${ }^{56}$.

En el caso de las variables binarias la estimación es un poco diferente, ya que lo que se indica es el cambio en probabilidad entre una persona que tiene un valor cero en la variable y otra que tiene un valor uno en ésta (y valores promedio en todo el resto de las variables). En otras palabras, el punto de referencia de la variable estudiada no es su promedio muestral (como en el caso de la nota de la madre) sino que es la ausencia de la característica indicada por la variable ${ }^{57}$.

Luego de esta aclaración, y para facilitar la exposición de los resultados, al hablar de la magnitud del efecto de una característica dada en la probabilidad de iniciación sexual, o en la probabilidad de cuidado, omitiremos repetir cada vez que esta estimación del efecto es ceteris paribus, y que los efectos marginales se evalúan en el valor promedio del resto de las variables.

Descriptivos básicos: en todos los modelos analizados ser mujer es un determinante muy importante y significativo de la iniciación sexual. Las mujeres se inician más tarde que los hombres. El hecho de ser mujer disminuye en más de 20 puntos porcentuales la probabilidad de ser sexualmente activo. Respecto del efecto de ser mujer en el cuidado y prevención cuando ocurre una relación, éste no es significativo.

La edad es un predictor potente de la conducta sexual de los jóvenes, en especial de su iniciación. Esto era de esperarse ya que es justamente la juventud la época en la que la mayor parte de los indivi-

${ }^{55}$ Cuando todo el resto de las variables se ubica en valor promedio.

${ }^{56}$ Suponiendo que todo el resto de las variables se ubica en el promedio muestral.

${ }^{57}$ Se hace así porque que el valor "promedio" de una variable indicadora es un número que está entre cero y uno. Por ejemplo, el promedio muestral de "cristiano no católico" es 0,152. Este promedio nos indica que el 15,2\% de la muestra reporta pertenecer a ese grupo de denominaciones religiosas. Sin embargo, la realidad individual no permite cifras intermedias: o se es "cristiano no católico" o no se es. Los individuos de la muestra toman sólo valores cero o uno en esa variable. Poner el número 0,152 como punto de referencia, por tanto, no tiene sentido alguno cuando queremos estimar efectos individuales. Mucho más interesante es comparar un individuo con valor cero en la variable, con otro con valor uno (suponiendo que ambos son idénticos en todo el resto). 
duos inician su vida sexual. Mientras mayor es el joven, mayor la probabilidad de haber comenzado su actividad sexual, independiente de si estamos hablando de hombres o de mujeres. Respecto del efecto de la edad en la probabilidad de utilización de métodos de prevención del embarazo, nos encontramos con estimaciones que no son significativas.

Nivel socioeconómico: el nivel socioeconómico es determinante en la decisión de iniciarse sexualmente y en la decisión de tomar precauciones para evitar un posible embarazo. Sin embargo, los efectos en la iniciación sexual son significativos sólo cuando comparamos niveles socioeconómicos extremos. Un joven perteneciente al nivel E tiene 13 puntos porcentuales más de probabilidad de haberse iniciado sexualmente que un joven $\mathrm{ABC} 1$, pero cuando comparamos a un joven $\mathrm{ABC} 1$ con un joven del estrato $\mathrm{C} 2$, C3 o D, no encontramos diferencias significativas. Por otro lado, los efectos del nivel socioeconómico en la prevención del embarazo son más importantes: la probabilidad de que un joven de nivel E se cuide es en promedio 37,5 puntos porcentuales menor que la probabilidad de que un joven ABC1 se cuide. Esta diferencia es mayor en las mujeres (49,8 puntos porcentuales) que en los hombres (31,8 puntos porcentuales). El caso de los jóvenes de estrato socioeconómico D también es significativamente diferente del de los jóvenes $\mathrm{ABC} 1$, aunque aquí el efecto es sólo significativo para las mujeres. Una joven de estrato D tiene una probabilidad de cuidarse que es 23 puntos porcentuales inferior a la de una joven de estrato ABC1. Asimismo, una joven de estrato C3 tiene una probabilidad de cuidarse que es 19,2 puntos porcentuales inferior a la de una joven de estrato ABC1. Por otro lado, no se observan diferencias significativas entre los comportamientos de los jóvenes de estratos C2 y ABC1. Es muy posible que una de las razones que explican este marcado efecto del nivel socioeconómico en el comportamiento sexual de los jóvenes se deba a que estas variables están muy correlacionadas con una variable ausente en nuestro modelo: el nivel educativo de los padres ${ }^{58}$. Esta variable ha demostrado en numerosas ocasiones ser muy buena predictora del comportamiento juvenil, y la literatura muestra efectos en la línea de los aquí estimados (ver, por ejemplo, Oettinger, 1999, o Kirby,

${ }^{58}$ La ENJ contiene información sobre el nivel educativo de "la persona que aporta el ingreso principal al hogar". De hecho, esta variable se usa para determinar el nivel socioeconómico del joven. 
2007). La educación de los padres está muy correlacionada con el nivel socioeconómico y por tanto este último podría estar actuando como un proxy de la primera.

Relación de pareja: estas variables también presentan un comportamiento acorde con la teoría. Una mujer que está de novia o que pololea tiene mayor probabilidad de haber iniciado su vida sexual que una joven que reporta estar "andando"59. Una que reporta "andar" tiene también menor propensión a haber iniciado su vida sexual (44,5 puntos porcentuales menos) que la que está de novia y las mujeres que reportan estar solas tienen la menor de las probabilidades de haberse iniciado (56,2 puntos porcentuales menos) que las que están de novias. El caso de los hombres es distinto, no observándose efectos significativos de su pertenencia a alguna de estas categorías. Respecto del uso de métodos de prevención del embarazo en la última relación, el tipo de relación de pareja en que se encuentra el joven no parece tener efecto alguno. En general esto nos podría estar indicando que la tendencia a usar protección es intrínseca a la persona y no al tipo de relación en la que está involucrada. Este resultado se contradice con la teoría de que quienes están en una relación más "segura" tienden a "relajarse" o simplemente podría estar reflejando que la relación de pareja del individuo al momento de ser encuestado no necesariamente refleja el tipo de relación que éste tenía con su última pareja sexual (o sea, una persona “sola” puede haber reportado que no se cuidó en su última relación, pero esa última relación la pudo haber tenido en un período en el cual estaba pololeando).

Vida sexual: estas variables sólo están disponibles en la base de datos para los ya iniciados, por lo que sólo se utilizan en la predición del cuidado en la última relación sexual. En general, el tiempo transcurrido desde la primera relación sexual tiene un efecto marginalmente significativo (al 10\%, y sólo para la ecuación que involucra a la población total). Un año más de experiencia tendería a reducir la probabilidad de cuidado en la última relación en 1,6 puntos porcentuales. Esto nos indicaría que los jóvenes no "aprenden con la experiencia”, sino, al parecer, todo lo contrario. Pero hay una explicación alternativa para este efecto: quienes tienen mayor experiencia en promedio se iniciaron más jóvenes. Quienes se iniciaron más jóvenes en general tendrán

\footnotetext{
${ }^{59}$ No hay diferencias significativas entre los jóvenes que están de novios y los que pololean.
} 
menor probabilidad de cuidarse que quienes esperaron hasta tener más edad para comenzar su vida sexual. Esto ha sido corroborado en una serie de estudios recogidos en Kirby (2007). En su informe, el autor reporta que al parecer es un hallazgo bastante robusto el que "los jóvenes que comienzan a tener sexo a una edad más temprana tienen menores probabilidades de usar anticoncepción y tienen mayores probabilidades de afrontar un embarazo y/o transformarse en padres. Tienden también a acumular más compañeros/as sexuales a lo largo de su vida y tienen menos disposición al uso de condones” (p. 67).

Respecto de aquellos que tienen o han tenido alguna vez parejas del mismo sexo, nuestras estimaciones indican un efecto significativo sólo en mujeres. En general, las jóvenes homosexuales o bisexuales tienen una probabilidad de cuidarse que es 21,8 puntos inferior a la de aquellas que tienen relaciones heterosexuales. Esto se puede explicar porque estas parejas no están en riesgo de embarazo, y los métodos de prevención de ETS en parejas femeninas son más escasos. El caso de los bisexuales u homosexuales hombres no se diferencia significativamente del de los heterosexuales.

Personalidad: en la encuesta que origina nuestros datos sobre personalidad de los jóvenes (Quinta Encuesta del INJUV), sólo se permite a los jóvenes describirse mediante la elección de un máximo de tres características de personalidad. Por eso estas variables deben considerarse como los descriptores "principales" de su manera de ser. En ese sentido un joven que no elige la opción "sociable" no necesariamente es poco sociable, sino que considera que la sociabilidad no es uno de los tres rasgos preponderantes de su personalidad. Después de esta aclaración, vamos a los resultados de la estimación: los jóvenes, y en especial los hombres, que eligen las opciones "bueno para el carrete" o "sociable" tienden a iniciar su vida sexual de manera más precoz, aunque no usan protección con más frecuencia que aquellos que no eligen estas opciones ${ }^{60}$. Un joven de sexo masculino que se considera "bueno para el carrete" tiene una probabilidad de haberse iniciado que es 16,8 puntos porcentuales superior a la de alguien que no considera que ésa sea una de las tres característica principales que lo describen.

${ }^{60}$ En estricto rigor, las variables de personalidad "sociable” y "bueno para el carrete" tienen alguna potencialidad de endogeneidad: es posible que un joven se autoconsidere "bueno para el carrete" o "sociable" porque se inició temprano (causalidad inversa). 
Los hombres jóvenes que se autodenominan "sociables" tienen una probabilidad de haberse iniciado 14,2 puntos sobre la de quienes no eligieron la alternativa. Por otro lado, los hombres "tranquilos" tienen una probabilidad de iniciación que es 10,7 puntos inferior a la de los jóvenes que no eligen esa opción. Quienes se autodenominan "consumistas” tienden a iniciarse antes (su probabilidad de iniciación es 11 puntos superior a la de quienes no eligen esta alternativa), aunque esta estimación es sólo marginalmente significativa (10\%) y pierde completamente la significancia cuando se dividen las muestras según sexo. Respecto del cuidado en la última relación, cuando quien se autodenomina "consumista" es mujer, la probabilidad de cuidado cae en 17,4 puntos respecto de quienes no eligen la opción. Este efecto es marginalmente significativo, y la estimación pierde significancia cuando se analiza a la población total o a los hombres. Los hombres que se autodenominan "trabajadores" tienen una probabilidad de haberse iniciado sexualmente que es 7,9 puntos superior a la de sus congéneres que no eligen esa opción, efecto que es marginalmente significativo. Esto puede deberse a que estos jóvenes tienen mayor autonomía económica y esa mayor disponibilidad de recursos puede aumentar sus oportunidades sexuales. Este efecto no se observa en mujeres ni en la estimación para la muestra conjunta. Por otro lado, no se observa relación alguna entre ser "trabajador" y la probabilidad de haberse cuidado en la última relación sexual. Finalmente las mujeres que se autodenominan "prácticas" tienen una probabilidad de haber comenzado su actividad sexual que es 14,1 puntos superior a la de aquellas que no eligen esta alternativa. Estas mujeres también tienen una probabilidad de haberse cuidado que es 13 puntos porcentuales superior a la de aquellas que no eligen esa opción. Este efecto está ausente en hombres y en la población general. Finalmente cabe mencionar que quienes se autodenominan "solitarios”, “desordenados”, o "realistas" no muestran un comportamiento diferente, en lo que se refiere a iniciación sexual o al uso de métodos de prevención, del de quienes no eligen estas características.

Cultura sexual: la educación sexual recibida en el colegio o el nivel de conocimientos sobre prevención o transmisión del VIH no parecen ser determinantes de la iniciación sexual de los jóvenes. Esto podría indicar que la educación sexual impartida en nuestro país no ha tenido como objetivo retrasar la iniciación sexual de los jóvenes, o que, de existir ese objetivo, no se está logrando. Ahora, si miramos este 
resultado desde otra óptica nos damos cuenta de que por lo menos el acceso a educación sexual no estaría teniendo como efecto un adelanto en la iniciación sexual de los jóvenes. Esto es muy interesante ya que muchos grupos que están en contra de educar a los jóvenes en los métodos de prevención de la natalidad y ETS argumentan que este tipo de capacitación tendría el efecto no deseado de adelantar su iniciación. En general, la evidencia (ver Kirby, 2007, por ejemplo) muestra que son muy pocos los programas que tienen este efecto de adelantamiento, y al parecer nuestros resultados para Chile confirmarían la tendencia. Por otro lado, es importante destacar que la cultura sexual sí estaría afectando significativamente el comportamiento preventivo de los jóvenes, en particular de los hombres. Un hombre joven que reporta haber recibido educación sexual en su escuela tiene una probabilidad de haber tomado precauciones en su última relación sexual superior en 9,8 puntos a la de quien no recibió tal educación ${ }^{61}$. Asimismo, los hombres jóvenes que son incultos en lo que se refiere a métodos de prevención del VIH tienen una probabilidad de haberse cuidado en su último encuentro sexual que es inferior en 18,2 puntos que la de aquellos que tienen cultura de prevención del sida. Estos resultados son muy interesantes, ya que nos indican que existe todavía un espacio de educación de los jóvenes que tiene algún impacto en su comportamiento. Nuestras tablas descriptivas (tabla $\mathrm{N}^{\circ}$ 9) indican que sólo el 44,4\% de los jóvenes de la muestra reportan haber recibido educación sexual (el 42,5\% de los hombres), y el 20,3\% de los jóvenes no conoce bien los mecanismos de transmisión del sida (20,4\% en caso de los hombres). Si estos jóvenes recibiesen la educación adecuada, podría aumentar bastante su nivel de protección cuando tengan una relación sexual. Por otro lado, estos datos nos informan que ha habido poca efectividad de las políticas educativas en las mujeres, que no han cambiado su comportamiento con la información recibida.

Todo lo anterior debe analizarse con cautela. No es recomendable caer en interpretaciones estáticas, como "la educación sexual no tiene como efecto un retraso en la edad de iniciación sexual” o como

${ }^{61}$ Sin embargo, también podría argumentarse que estos resultados serían espurios, ya que es posible que los jóvenes que recuerdan haber tenido educación sexual son los más responsables. Por otro lado, esta línea de argumentación no es válida para las variables de cultura sexual, ya que ésta fue evaluada directamente en la encuesta a través de preguntas de conocimiento. 
"la educación sexual no tiene efectos en el comportamiento sexual preventivo de las mujeres". Al contrario, estos resultados nos indican que la educación sexual chilena, tal como ha sido formulada, no ha tenido los efectos esperados en el comportamiento preventivo de las mujeres ni tampoco ha logrado retrasar la edad de iniciación sexual, pero sí ha tenido algunos efectos acotados a la población masculina. Esto nos indica que la educación sexual de nuestro país tiene algún potencial para generar cambios en el comportamiento juvenil, pero que su formulación e implementación hasta el momento pueden no ser las óptimas. Existen programas de educación sexual que sí han demostrado lograr estos objetivos y que podrían aplicarse en el futuro en nuestro país.

Valores: los valores liberales generales son significativos predictores de la iniciación sexual de los jóvenes. Un joven que tiene un punto más en esta escala aumenta su probabilidad de iniciación en 7,4 puntos (9,2 para las mujeres, 5,6 para los hombres). Este efecto es bastante notable sobre todo si consideramos que la escala de estos valores consta de 5,3 puntos. Ello indica que la diferencia en la probabilidad de iniciación entre el más conservador y el más liberal es de alrededor de 39 puntos porcentuales ${ }^{62}$. Por otro lado, los valores liberales generales no tienen ningún poder predictivo de la conducta sexual en lo que se refiere a uso de métodos de anticoncepción. Los valores liberales particulares, por otro lado, no tienen efecto en la iniciación sexual de los jóvenes, pero sí inciden (con significancia marginal) en la conducta de protección de las mujeres. Mientras mayor es el nivel de valores liberales particulares, estas jóvenes tienden a protegerse más de un eventual embarazo. Como vimos más arriba, altos niveles del índice de valores liberales particulares reflejan a personas que, aunque pueden estar de acuerdo con prácticas "liberales" como el aborto en caso de peligro de vida de la madre o la eutanasia, están en desacuerdo con las propuestas liberales menos aceptadas por la población en general (legalización de la marihuana) y tienen una visión más bien conservadora del matrimonio (desaprueban el divorcio o el matrimonio entre homosexuales, y valoran el matrimonio como un proyecto para toda la vida). Esta visión conservadora en lo que se refiere a las relaciones de pareja podría estar empujando a estos jóvenes a tener mayor conciencia de las repercusio-

\footnotetext{
${ }^{62}$ Este valor es aproximado, porque los efectos marginales varían según el punto en el que se evalúen.
} 
nes de un eventual embarazo que las obligue a tomar decisiones bajo presión.

Relaciones de familia: una buena relación con la madre es un predictor bastante significativo del retraso de la iniciación sexual de los jóvenes en general, sin importar su sexo. Un punto más en la nota de la madre se traduce en una caída en la probabilidad de haberse iniciado sexualmente de 7,4 puntos (9,2 para las mujeres y 5,6 para los hombres). Sin embargo la nota de la madre no parece tener efecto alguno en la probabilidad de que un joven se proteja durante una relación sexual.

La relación con el padre también es determinante, especialmente para las mujeres, donde un punto más en la nota asignada implica una disminución de 2 puntos en la probabilidad de iniciación. El efecto de la relación con el padre en hombres es marginalmente significativo ${ }^{63}$ e indica que a mayor nota del padre, mayor es la probabilidad de que éste se haya iniciado (un punto más en la nota implica 1,8 puntos más en la probabilidad de iniciación). La relación con el padre tampoco tiene efectos en la toma de precauciones anticonceptivas de los jóvenes. Llama la atención que un padre bien evaluado prediga una mayor precocidad en la iniciación sexual de su hijo hombre. Es posible que los adolescentes hombres entreguen una mejor nota a aquellos padres que son más permisivos con sus conductas. Esto está en línea con la evidencia internacional. Por ejemplo, Miller et al. (2001) comentan que los efectos de la cercanía y comunicación entre padres e hijos es el factor protector con evidencia más consistente a través de los diferentes estudios. Esta variable incidiría tanto en el retraso de la iniciación y en la disminución de la frecuencia sexual. Por otro lado, la supervisión parental (regulación y monitoreo de las actividades de los jóvenes, variable no incluida en nuestra estimación) estaría relacionada con un menor riesgo de embarazo en la mayoría de los estudios analizados por los autores (aunque se postula que podría existir una relación curvilínea donde los padres excesivamente autoritarios y controladores aumentarían el riesgo al igual que aquellos muy permisivos). Otro factor protector que disminuiría el riesgo de embarazo son los valores parentales en contra de las relaciones sexuales (o de las relaciones sexuales desprotegidas). 
El índice general de malas relaciones familiares también afecta, de manera marginalmente significativa, la probabilidad de iniciación. Un punto más en el índice produce un aumento en la probabilidad de iniciación sexual de 3,3 puntos. Si miramos en el Apéndice la Tabla $\mathrm{N}^{\circ} \mathrm{A}-2$ nos damos cuenta de que la escala de este índice tiene 4,4 puntos aproximadamente, lo que implica que la procedencia de una familia más armónica o de una familia más problemática haría una diferencia en la probabilidad de iniciación que bordearía los 14,5 pun$\operatorname{tos}^{64}$. Sin embargo, la significancia de esta estimación se pierde cuando separamos la muestra según sexo. En términos de la toma de precauciones frente a una relación sexual, el valor de este índice no parece tener mucha relevancia.

Por otro lado, el índice de dificultades económicas y de comunicación en la familia de origen del joven resulta significativo en la predicción del comportamiento sexual sólo de las mujeres. Un punto más en este índice lleva a un aumento de 4,1 puntos en su probabilidad de haber comenzado ya su vida sexual. Estas mujeres también tienen mayor predisposición a cuidarse: un aumento de un punto en el índice eleva en 4,6 puntos la probabilidad de haber tomado las precauciones adecuadas al momento de una relación sexual.

Confianza y discriminación: quienes tienen confianza en sus amigos tienen menor probabilidad de haberse iniciado sexualmente (7,1 puntos menos que quienes no la tienen). Sin embargo, esta variable resulta sólo marginalmente significativa $(\mathrm{p}<0,1)$ y pierde completamente la significancia al separar las muestras por sexo. El gusto de estar con los amigos tampoco tiene incidencia en el comportamiento sexual adolescente. Por otro lado, las variables de percepción de discriminación sí parecen ser mucho más predictivas del comportamiento juvenil en materia sexual.

Como era de esperarse, quienes se han sentido discriminados por su apariencia tienen menor probabilidad de iniciarse sexualmente, ya que es posible que les resulte más difícil encontrar pareja. Este efecto es significativo para las mujeres y no para los hombres. Una mujer que reporta este tipo de discriminación tiene 12,2 puntos menos de probabilidad de iniciación. La variable para discriminación por apariencia sin embargo no es un predictor significativo de la toma de

${ }^{64}$ Este cálculo es sólo aproximado, ya que el valor del efecto marginal varía según el punto en el que se lo evalúa. 
precauciones al tener una relación sexual. Quienes se sienten discriminados por sus pares no tienen diferencias con quienes no se sienten así en términos de iniciación sexual, pero sí en términos de cuidado. Este efecto se da en hombres y es de magnitud bastante importante: la diferencia en la probabilidad de cuidarse durante una relación sexual entre quienes no se sienten discriminados por sus pares y quienes sí tienen esa percepción es de 17,6 puntos porcentuales. Por otro lado, la discriminación por parte de carabineros o algún tipo de autoridad es un predictor bastante significativo de la iniciación sexual. Como se explicó con anterioridad, es posible que esta variable esté actuando como una proxy para el nivel de rebeldía del joven. Quienes perciben ese tipo de discriminación tienen una probabilidad de haberse iniciado 12,8 puntos superior a quienes no la perciben (11,7 para mujeres, 14,1 para hombres). Esta variable sin embargo no tiene efectos significativos en la probabilidad de tomar precauciones al involucrarse en una relación sexual.

Religión: profesar alguna religión en particular no tiene al parecer ninguna injerencia en el comportamiento de los jóvenes ni en lo que respecta a su iniciación ni al uso de métodos de prevención del embarazo. Sólo encontramos un efecto marginalmente significativo de la religión católica en la iniciación de las mujeres, que va en la dirección de aumentar la probabilidad de haber tenido ya su primera relación. Este efecto puede deberse a que la denominación católica en nuestro país es muy común y reúne a personas muy diversas y con perfiles muy variados.

Las variables que mejor explican la conducta sexual de los jóvenes se relacionan con su nivel de observancia de cualquier religión, representada en nuestro análisis por las variables que recogen la frecuencia de asistencia a ritos religiosos. Recordemos que estas variables de observancia fueron diseñadas para captar efectos incrementales, por lo que la estimación del efecto de la asistencia semanal nos entrega una idea de la diferencia entre quienes asisten semanalmente y quienes asisten mensualmente. Al mismo tiempo, la estimación del efecto de la asistencia mensual nos indica que hay una diferencia entre quienes asisten a los servicios con esta frecuencia y quienes asisten menos de una vez por mes. Los resultados estimados son interesantes: aunque la asistencia mensual a servicios religiosos no tiene efectos en la iniciación sexual (cuando comparamos con quienes asisten con frecuencias 
inferiores a ésa), quienes asisten a servicios religiosos semanalmente tienen una probabilidad de haberse iniciado que es inferior en 18,1 puntos porcentuales a la de quienes asisten mensualmente. Este efecto es especialmente importante en magnitud en los hombres (para quienes la probabilidad de iniciación cae 22,4 puntos), aunque en el caso de las mujeres también hay un efecto grande y significativo (18,4 puntos). Por otro lado, el efecto de la frecuencia de asistir a los servicios incide positivamente en el uso de protección en una relación sexual: quienes asisten una vez al mes a algún servicio religioso tienen una probabilidad de cuidarse que es 14 puntos porcentuales superior a la de quienes asisten con frecuencia inferior o no asisten. La asistencia semanal no incrementa ni disminuye el cuidado. En suma, la observancia religiosa la podemos dividir en alta (asistencia semanal), media (asistencia mensual) y baja (asistencia escasa o inexistente). Si consideramos como punto de referencia la observancia baja, nos encontramos con que una observancia media no afecta la edad de iniciación pero sí incrementa la probabilidad de tomar precauciones en una relación sexual. Si incrementamos ahora la observancia a un nivel alto, vemos que los jóvenes de este grupo no se diferencian de los de observancia media en lo que se refiere al cuidado, pero sí se diferencian en su edad de iniciación sexual, que aumenta. El efecto en la iniciación sexual se debe probablemente a que la mayor parte de las religiones enfatizan la abstinencia como un valor. Por otro lado, el efecto en el cuidado puede deberse a que quienes tienen algún nivel de involucramiento religioso (medio o alto) están al tanto del carácter negativo que sus iglesias (y posiblemente sus familias, que pertenecen a estas iglesias) confieren al sexo sin compromiso. Por ello tienen especial cuidado en no quedar en evidencia y por ende se preocupan más de prevenir las consecuencias negativas o inesperadas de estas conductas. El efecto "protector" de la afiliación activa a una religión ha sido documentado por Kirby (2007), quien a su vez reporta que tener una familia o un entorno que desaprueba el sexo premarital o adolescente también tiene efectos protectores. Este efecto protector de la asistencia religiosa también ha sido documentado en Chile para el caso del consumo de drogas (Neckelmann, 2009).

Situación laboral individual: este grupo de variables, como ya discutimos, tiene alguna potencial endogeneidad debido a que no sólo la situación laboral afectaría el comportamiento sexual sino que podría 
haber una causalidad inversa: jóvenes que no tuvieron precauciones al practicar sexo pueden llegar a tener un hijo, lo que les afectaría en sus prospectos y decisiones laborales. Esta endogeneidad debiera ser especialmente importante en mujeres pero no necesariamente inexistente en hombres, y sus efectos debieran aumentar según se incrementa la edad promedio de la muestra. Es por ello que estas variables no están incluidas en el modelo reportado en la Tabla $\mathrm{N}^{\circ} 10$ y sólo se incluyen en un modelo alternativo, cuyos resultados detallados están disponibles en Dussaillant (2010). La Tabla $\mathrm{N}^{\circ} 11$ muestra los resultados de este modelo para las variables de situación laboral individual. No está demás recalcar que debemos ser cautos a la hora de tomar estas estimaciones demasiado al pie de la letra (sobre todo en lo que se refiere a su magnitud) porque podrían estar sesgadas.

El estatus laboral tiene efectos significativos en la iniciación sexual de hombres y mujeres. Una mujer que estudia tiene una probabilidad de haberse iniciado 10,6 puntos inferior que otra que no estudia. Esto tiene dos explicaciones: por un lado una mujer que ya ha comenzado su actividad sexual y es madre tiene una menor posibilidad de embarcarse en un proyecto de estudio (ahí está la causalidad inversa de la que hablábamos). Por otro lado, una mujer que está estudiando tiene un proyecto de vida muy definido y va a velar por que éste no se vea truncado. Además, los estudiantes tienen menos tiempo libre para salir de juerga y también para encontrar una pareja. Y agregamos que las mujeres estudiantes no se diferencian del resto en el uso métodos anticonceptivos.

TABLA N ${ }^{\circ}$ 11: RESULTADOS MODELO ALTERNATIVO CON VARIABLES DE SITUACIÓN LABORAL INDIVIDUAL. EFECTOS MARGINALES

\begin{tabular}{|c|c|c|c|c|c|c|}
\hline \multirow{2}{*}{$\begin{array}{l}\text { Estatus laboral } \\
\text { estudia }\end{array}$} & \multicolumn{3}{|c|}{$\begin{array}{c}\text { Ecuación principal } \\
\text { (variable dependiente: } \\
\text { cuidado en la última relación) }\end{array}$} & \multicolumn{3}{|c|}{$\begin{array}{l}\text { Ecuación de selección } \\
\text { (variable dependiente: } \\
\text { sexualmente activo) }\end{array}$} \\
\hline & $\begin{array}{r}-0,0306 \\
(0,0365)\end{array}$ & $\begin{array}{r}0,0375 \\
(0,0474)\end{array}$ & $\begin{array}{r}-0,0703 \\
(0,0535)\end{array}$ & $\begin{array}{r}-0,0718^{*} \\
(0,0395)\end{array}$ & $\begin{array}{r}-0,106 * * \\
(0,0532)\end{array}$ & $\begin{array}{r}-0,0179 \\
(0,0563)\end{array}$ \\
\hline trabaja & $\begin{array}{c}0,0930^{*} \\
(0,0439)\end{array}$ & $\begin{array}{r}0,182 * * * \\
(0,0450)\end{array}$ & $\begin{array}{r}0,0438 \\
(0,0630)\end{array}$ & $\begin{array}{c}0,104 * * \\
(0,0446)\end{array}$ & $\begin{array}{r}0,0840 \\
(0,0712)\end{array}$ & $\begin{array}{r}0,145^{* * *} \\
(0,0498)\end{array}$ \\
\hline ousca & $\begin{array}{r}0,0315 \\
(0,0384)\end{array}$ & $\begin{array}{r}0,0739 \\
(0,0493)\end{array}$ & $\begin{array}{r}0,00684 \\
(0,0529)\end{array}$ & $\begin{array}{r}0,0198 \\
(0,0379)\end{array}$ & $\begin{array}{r}-0,0157 \\
(0,0524)\end{array}$ & $\begin{array}{r}0,0584 \\
(0,0486)\end{array}$ \\
\hline
\end{tabular}


Al mismo tiempo, los hombres jóvenes que trabajan tienen mayores probabilidades de haberse iniciado sexualmente. Esto está en línea con la evidencia internacional. Kirby (2007) argumenta: “...los jóvenes en trabajos pagados, especialmente aquellos que trabajan más de 20 horas semanales, tienen mayor probabilidad de iniciarse, tienen sexo con mayor frecuencia y tienden a tener más parejas sexuales. El trabajo pagado podría aumentar la sensación de independencia de los jóvenes, su movilidad y sus oportunidades sexuales” (p. 65). Estos jóvenes sin embargo no se diferencian del resto en términos de precauciones en sus relaciones sexuales. Son las mujeres trabajadoras las que sí tienen un comportamiento diferente en cuanto a la prevención del embarazo. Una mujer que trabaja tiene una probabilidad de cuidarse en sus relaciones sexuales que es 18,2 puntos superior a la de una que no lo trabaja. Finalmente, quienes buscan trabajo no parecen tener, en la población joven general, ninguna predisposición especial en referencia a su iniciación o conducta sexual posterior.

Variables contextuales (comunales): desempleo hombres 30-50 años: esta variable es muy interesante porque refleja el estado del mercado laboral en la comuna de residencia del joven. En ese sentido, sirve de aproximación al ambiente laboral que enfrenta el joven en particular y también su familia. No es una novedad que el índice de desempleo afecta el comportamiento sexual de los jóvenes. De hecho, existen otros trabajos que han verificado tales efectos (ver, por ejemplo, Arkes y Klerman, 2009). Nuestras estimaciones arrojan que la desocupación comunal no tendría efecto alguno en la iniciación sexual de los jóvenes, pero sí en el comportamiento preventivo de los ya iniciados, especialmente hombres. Un punto porcentual más en las estadísticas de desocupación comunal predicen una caída de 2,2 puntos en la probabilidad de que un joven (hombre) adolescente tome precauciones a la hora de tener relaciones sexuales. La explicación que Arkes y Klerman (2009) dan a este fenómeno tiene que ver con que los jóvenes que tienen más tiempo a su disposición, menos aspiraciones en lo que se refiere a la consolidación de una carrera laboral y que soportan una mayor carga de estrés se valen del sexo como una manera de sobrellevar sus desilusiones. Los autores argumentan que cuando la economía se fortalece, habrá más modelos de conducta o de roles para el joven que estará trabajando muchas veces con una carrera laboral 
establecida. "Un futuro brillante es el mejor anticonceptivo"65 y es posible que una economía fuerte produzca la percepción de un futuro brillante. Por otro lado un alto nivel de desempleo podría inducir el aumento de la fertilidad ${ }^{66}$ debido a que los costos de oportunidad de tener un hijo disminuyen. Además, en esos contextos el tiempo libre de los jóvenes aumenta, y con ello el consumo de alcohol y drogas, los que incitan a los comportamientos riesgosos (de hecho Arkes, 2007, documenta que la prevalencia de alcohol y drogas disminuiría cuando la economía está fuerte).

Variables contextuales (comunales) drogas: es muy importante dejar en claro que éstas son variables de contexto y no variables individuales. En ese sentido, debemos mirarlas como medida del ambiente que rodea al joven y no como un indicador del comportamiento de éste. Hubiera sido muy bueno tener acceso a información sobre el consumo de drogas particular de cada joven, ya que la evidencia apunta a que este tipo de variables tiene una incidencia importante en su comportamiento sexual. Sin embargo sólo conocemos el valor promedio del consumo en la comuna de residencia del joven y eso no es necesariamente un indicador de consumo individual (aunque probablemente tenga alguna correlación). En ese sentido hay que ser muy cautos al analizar las estimaciones cuidando de interpretar los efectos como efectos de contexto y no como efectos individuales. Debemos interpretar los estimadores como respondiendo a la pregunta ¿cómo afecta un mal ambiente — referido a consumo o tráfico de substancias - al comportamiento sexual del joven?, y no a la pregunta ¿cómo afecta el consumo de drogas al comportamiento sexual del joven? Por otro lado, estas variables agregadas a nivel comunal también nos pueden estar indicando un comportamiento individual, por lo que tampoco podemos estar seguros de que las estimaciones nos reflejen un efecto puramente atribuible al ambiente ${ }^{67}$. Además, nuestros índices de drogas comunales pueden quizá interpretarse como una aproximación (muy imperfecta) al efecto par: a mayor drogadicción comunal, mayor la probabilidad de que el grupo de pares del joven tenga mayor disposición

${ }^{65}$ Cita que Arkes y Klerman atribuyen a Marian Wright Edelman.

${ }^{66}$ Tanto por la disminución de uso de métodos de prevención como debido a un aumento de la frecuencia sexual. Esta última variable no la estudiamos en nuestra investigación.

${ }^{67}$ Una mejor separación de los efectos individual y de contexto la hubiéramos obtenido de haber tenido los datos de consumo individual además de los datos de consumo agregado. 
a las drogas ${ }^{68}$. Finalmente, una comuna donde las drogas son más comunes también puede estar indicando la residencia en barrios desorganizados y pobres, factor considerado como de riesgo en la literatura sobre sexualidad juvenil (ver por ejemplo Miller et al., 2001, y Kirby, 2007)

Los resultados demuestran que efectivamente existe una relación entre nivel de drogas comunal y comportamiento sexual. En las zonas donde la marihuana es más prevalente los jóvenes (especialmente hombres, aunque también mujeres) tienden a iniciar su actividad sexual más temprano. Por otro lado, en las comunas donde el consumo de alcohol es más importante, las mujeres tienden a iniciarse más precozmente. Si miramos las escalas de estos índices en la Tabla $\mathrm{N}^{\circ} 9$ notamos que la escala para el índice de problemas con el alcohol tiene 1,4 puntos mientras que la escala para el índice de problemas con marihuana tiene 5,5 puntos. De esto y recurriendo a las estimaciones de los efectos marginales reportados en la Tabla $\mathrm{N}^{\mathrm{o}} 10$ podemos concluir que la diferencia en la probabilidad de iniciación sexual entre la comuna donde se consume más marihuana y aquella en que se consume menos es de aproximadamente 32 puntos para los hombres y 18 puntos para las mujeres. Por otro lado, la diferencia en la probabilidad de iniciación sexual entre la comuna donde se consume más alcohol y aquella en que se consume menos es de aproximadamente 30 puntos para las mujeres. Los índices recién mencionados, sin embargo, no parecen ser determinantes del nivel de protección practicada por los jóvenes al tener relaciones sexuales. El nivel de tráfico en la comuna tampoco parece incidir en la conducta sexual de los jóvenes, por lo menos de acuerdo a los resultados de las estimaciones asociadas a nuestro modelo.

\section{DISCUSIÓN Y PROPUESTAS DE POLÍTICA}

Una conclusión inicial y general a partir de nuestro análisis empírico es que los jóvenes chilenos no se diferencian demasiado de los jóvenes de otros países en cuanto a costumbres sexuales. Nuestro análisis detectó factores protectores y de riesgo que están en línea con la evidencia internacional, lo que nos permite suponer que las interven-

\footnotetext{
${ }^{68}$ Recordar que los índices de drogadicción generados consideran sólo la población menor de 30 años de la comuna.
} 
ciones que se han hecho con éxito en otros lugares podrían ser efectivas también en Chile.

Por otro lado, los factores de riesgo y factores protectores aquí establecidos tienen un diferente potencial de intervención mediante política pública. Factores de personalidad o religiosidad por ejemplo, son difícilmente modificables, mientras factores que implican la entrega de información y adquisición de conocimiento por parte de los jóvenes tienen un potencial mucho mayor.

No debemos olvidar además que la parte empírica de este trabajo es un aporte general y por lo tanto las propuestas de política que presentaremos a continuación son propuestas iniciales, basadas no sólo en la evidencia cuantitativa estimada sino también en la evidencia internacional. Cualquier iniciativa concreta en esta línea requiere de mayor análisis que el presentado en este trabajo.

La prevención de actitudes excesivamente riesgosas por parte de jóvenes y adolescentes es sin duda un desafío difícil de lograr. Ello podría deberse a que los mecanismos de toma de decisiones que éstos utilizan no estarían bien sincronizados, en parte debido a su falta de madurez en el ámbito psicosocial. Esto no significa que los jóvenes no sean capaces de tomar decisiones racionales, sino que muchas veces el mecanismo racional se vería anulado por otros mecanismos asociados a una red socioemocional todavía inmadura. En ese sentido, mejorar las herramientas informativas en busca de que el joven tome mejores decisiones (apelando a su red cognitiva) sólo tendría efectos acotados.

Sin embargo, el que estos efectos sean acotados no implica ausencia de efecto. Como vimos en las estimaciones, los jóvenes que conocen los mecanismos de transmisión del VIH y quienes han recibido algún tipo de educación sexual tienen comportamientos menos riesgosos que sus congéneres desinformados. En ese sentido, países con niveles educativos relativamente bajos en estos aspectos, como por ejemplo Chile, tienen aún bastante camino por recorrer en el proceso de diseñar programas educativos informativos que permitan a los jóvenes sopesar de mejor manera los eventuales costos y beneficios de sus acciones ${ }^{69}$. Es probable que el avance por esa vía (la

${ }^{69} \mathrm{Al}$ respecto es interesante mencionar un estudio que se realizó en Argentina (no tenemos conocimiento de algo similar realizado en Chile) que recogió las preguntas que tenían los jóvenes escolares respecto de temas de sexualidad. El estudio revela un importante nivel de confusión en estos jóvenes, confusión que probablemente es conducente a un inadecuado 
educativa-informativa) sea significativo, ya que estamos partiendo de un punto en el cual la desinformación es bastante grande. Sin embargo, aun teniendo una población juvenil perfectamente informada, la evidencia nos indica que el problema seguiría vigente (aunque en una magnitud inferior), debido a que los jóvenes no siempre actuarían de manera acorde con lo que "en frío" evalúan como la conducta que más les conviene.

En ese sentido, es importante que el país desarrolle estrategias complementarias a la informativa. En general, además de informar se podrían realizar esfuerzos de prevención normativa para cambiar la mentalidad de jóvenes con una disposición quizá demasiado proclive hacia el sexo desprotegido. Al parecer eso es lo que han logrado algunos países europeos donde los jóvenes consideran "estúpido e irresponsable" tener sexo sin protección ${ }^{70}$.

Una posible política que busca explotar el efecto par, importante determinante de las conductas riesgosas juveniles, es mediante campañas positivas que demuestren al joven que sus pares son menos promiscuos y descuidados de lo que ellos creen. Los jóvenes son tremendamente sensibles a la presión de los pares y esta manera de influir podría tener buenos resultados. Un ejemplo de esto podría pasar por entregar información real a los jóvenes sobre la proporción de individuos de su misma edad en su comuna o el país que ya han comenzado su vida sexual. Muchas veces los jóvenes han sobredimensionado esta información, ya que es común que algunos de sus compañeros alardeen de una vida sexual que no es tal. Esto podría inducirlos a tener un comportamiento que creen es masivo cuando no lo es. Si a un joven se

balance entre costos y beneficios de tener una relación sexual sin protección. El nivel de desinformación reportado es bastante amplio y variado. Por ejemplo, algunas preguntas que surgieron del estudio (realizadas por escolares), además de las típicas sobre biología y prevención del embarazo y ETS, fueron ¿por qué hay gente que disfruta del sexo usando la violencia?, ¿es doloroso ir al ginecólogo?, ¿se puede ser estéril y eyacular?, ¿si una persona tiene sexo oral con un violador, se toma como violación? (Goldstein y Glejzer, 2008).

${ }^{70} \mathrm{Sin}$ embargo, debemos ser cautelosos en este sentido. No sabemos realmente por qué en Europa se ha logrado que los jóvenes tengan la mentalidad que tienen. Es posible que haya sido debido a las campañas y medidas gubernamentales descritas. Pero también es posible que se deba a un problema estructural más profundo y difícil de intervenir que se relaciona con el alto nivel de secularidad de los pueblos europeos citados como ejemplo en los artículos comparativos aludidos en el texto, y al bajo nivel de desigualdad que hay en esas economías. 
le informa de manera seria que, por ejemplo, el $80 \%$ de su generación en la comuna aún no ha comenzado su vida sexual, es muy probable que este joven se sienta más seguro como para decidir postergar su iniciación ${ }^{71}$. Para ello es fundamental recoger información lo más fidedigna posible respecto al verdadero comportamiento de estos jóvenes. Ello implica en lo posible encuestas con un alto nivel de privacidad donde el joven pueda responder sin que el encuestador se entere de su respuesta.

El efecto par también puede explotarse mediante intervenciones en sectores donde los grupos juveniles tienden a tomar más riesgos que lo normal. Por ejemplo, como vimos en nuestra estimación, probablemente intervenciones efectivas en el ámbito del consumo de drogas en ciertas comunas podrían tener efectos deseables también en la conducta sexual de estos individuos por dos vías: primero, disminuyendo la probabilidad de ese consumo y por ende de que el joven pierda la noción de la realidad y se embarque en conductas que en otro contexto hubiera evitado, y segundo, disminuyendo la presión del grupo de amigos. Es muy probable que el efecto de contexto no se restrinja solamente al nivel de consumo de drogas y alcohol prevalente en el sector donde vive el joven. Otros factores como la proporción de jóvenes con historial criminal en la zona, o la proporción de hogares disfuncionales, etc., también podrían incidir de manera indirecta en el comportamiento de los jóvenes. No debemos olvidar, sin embargo, que las intervenciones recién mencionadas son indirectas y probablemente menos efectivas y de más difícil implementación que cualquier programa que ataque directamente el problema.

${ }^{71}$ Un experimento de ese tipo se realizó en Estados Unidos, pero esta vez con el objeto de reducir el consumo de tabaco y alcohol entre los jóvenes de Montana. Likenbach (2003) y Likenbach y Perkins (2003) describen una campaña educacional de gran escala adoptada por el estado para informar a la gente que la gran mayoría de los ciudadanos no consume alcohol. Uno de los avisos busca corregir percepciones equivocadas al afirmar que "la mayoría (81 por ciento) de los estudiantes universitarios de Montana toma cuatro o menos bebidas alcohólicas a la semana”. Campañas similares se han realizado en ese estado para reducir el consumo de tabaco. Los autores reportan una mejora sustancial en la precisión de las percepciones de los jóvenes y disminuciones estadísticamente significativas en el consumo. De hecho, en Montana existe un organismo dedicado exclusivamente a este tipo de campañas denominado Most of Us (www.mostofus.org) orientado al "marketing de normas sociales" (ver Thaler y Sunstein, 2008, para una discusión del tipo de programas que apelan al comportamiento de "rebaño" inherente al ser humano y especialmente a los jóvenes). 
El efecto de la religiosidad en el comportamiento sexual, sobre todo en el timing de la iniciación, es un factor a considerar. La religiosidad es un factor protector, aunque no fácilmente modificable mediante política pública. Sin embargo, debemos examinar si tiene sentido confrontar los programas de educación sexual con la visión de la iglesia respecto de cómo deberían ser educados sus feligreses activos. Por eso quizá no es recomendable que los programas diseñados por el gobierno se transformen en una imposición para quienes están en desacuerdo con el enfoque ofrecido, aunque en este sentido aún falta exploración más profunda que la aquí presentada.

Por otro lado, nuestros datos indican que es necesario diseñar programas alternativos de política pública que tomen en cuenta la realidad sexual de los jóvenes de hoy en día. Estos programas deben informar a los jóvenes sobre temas biológicos de su sexualidad y deben incluir capacitación sobre los distintos métodos de prevención disponibles y su efectividad en la prevención del embarazo ${ }^{72}$ y enfermedades de transmisión sexual. Al mismo tiempo, es posible que una intervención que busque capacitarlos en estrategias de negociación y liderazgo que les permitan sobrellevar y contrarrestar la presión de sus pares y su pareja tenga alguna efectividad. De hecho, uno de los programas más efectivos ${ }^{73}$ en Estados Unidos para la prevención del embarazo adolescente, el programa Reducing the Risk: Building Skills to Prevent Pregnancy, STD\&HIV, tiene como eje programático principal el desarrollo de este tipo de estrategias. Es posible también, al menos en ciertas comunidades, incluir en estos programas alguna capacitación cuyo objetivo sea explicar a los jóvenes el sentido profundo de una relación de pareja estable, contexto en el cual la relación sexual se da de forma más plena. Los programas integrales de educación sexual, que incluyen a la vez información sobre anticoncepción y prevención de

${ }^{72}$ Por ejemplo, el joven debe saber que los métodos reversibles más seguros en la prevención del embarazo son los hormonales o el DIU, también debe saber que la píldora del día después tiene una efectividad bastante menor, debe saber que estos métodos no previenen contra las enfermedades de transmisión sexual, y debe tener en cuenta que los métodos naturales, para ser efectivos, deben considerar más factores que el simple conteo de días a partir de la última menstruación.

${ }^{73}$ Éste es sólo uno de varios programas que han mostrado comprobada efectividad en los Estados Unidos. Tiene la ventaja además de haber sido replicado con éxito. Para conocer todos los programas bien evaluados en ese país, ver Kirby (2007) o Advocates for Youth (2008). 
ETS estudiados por Kirby (2007), han sido los más exitosos (en el contexto de Estados Unidos) para la prevención del embarazo y enfermedades de transmisión sexual. La evidencia hasta ahora recogida sobre los programas que buscan sólo potenciar la abstinencia sexual no es concluyente aun, por lo que sería interesante realizar más investigación en esta área. Finalmente, también sería interesante explorar los programas de paternidad responsable y sus efectos en el embarazo adolescente.

Por otro lado, un aporte significativo a la investigación de política pública pasa por enriquecer las bases de datos existentes en nuestro país. Por ejemplo, con los datos que hoy en día existen no es posible medir la relación entre consumo individual de drogas y comportamiento sexual. Un aporte importante en esta área sería lograr la coordinación entre las encuestas del INJUV y del Conace de manera que los individuos encuestados fuesen los mismos. Así podríamos medir con mucha más fineza el verdadero efecto del consumo de alcohol y marihuana en el comportamiento sexual de los jóvenes. También sería interesante agregar nuevas preguntas a estas encuestas que permitan estudiar efectos en la actividad sexual juvenil de algunas características individuales y familiares que la literatura internacional ha establecido como relevantes. Por ejemplo, Miller et al. (2001) explican que los principales factores protectores frente a un embarazo adolescente tienen que ver con la calidad de las relaciones con los padres y con el nivel de monitoreo y supervisión parental. Los autores también explican que algunas de las variables más importantes en la predicción del embarazo adolescente son: la residencia en barrios desorganizados y pobres, la presencia de uno solo de los progenitores, la existencia de hermanos mayores activos sexualmente o con historial de embarazo adolescente y el haber sido víctima de abuso sexual. Además, existen factores de riesgo biológicos, como lo sería una pubertad temprana. Aunque tuvimos la posibilidad de testear la importancia de algunas de estas variables en el contexto chileno, otras no estaban disponibles en los datos. Sería bastante interesante que la encuesta del INJUV agregase preguntas que pudieran servir para generar variables del tipo recién descrito, además de incluir evidencia sobre el nivel de educación materno y paterno, historial de actividad criminal del joven, y algunas características particulares del grupo de amigos con los que este interactúa. 


\section{APÉNDICE}

\section{Construcción de índices de "valores liberales"}

TABLA N ${ }^{\circ}$ 12: $\quad$ ANÁLISIS DE COMPONENTES PRINCIPALES PARA VARIABLES VALÓRICAS

\begin{tabular}{lcc}
\hline Cuán de acuerdo está con & $\begin{array}{c}\text { Factor 1 } \\
\text { Valores liberales } \\
\text { generales }\end{array}$ & $\begin{array}{c}\text { Factor 2 } \\
\text { Valores liberales } \\
\text { particulares }\end{array}$ \\
\hline El divorcio & 0,24196 & $-0,20306$ \\
Matrimonio homosexual & 0,23247 & $-0,23062$ \\
Legalizar la marihuana & 0,23388 & $-0,13611$ \\
La píldora del día después & 0,2507 & 0,00248 \\
El matrimonio como institución para toda la vida & $-0,12647$ & 0,6671 \\
La eutanasia $^{1}$ & 0,25906 & 0,44394 \\
El aborto terapéutico $^{2}$ & 0,25133 & 0,41107
\end{tabular}

${ }^{1}$ En la pregunta se incluye la definición de eutanasia dada por la OMS: “Acción del médico que provoca deliberadamente la muerte del paciente”.

${ }^{2}$ Se incluye definición de este tipo de aborto como: "Aborto que se realiza cuando está en peligro la vida de la madre”.

\section{Construcción de índices sobre relaciones familiares}

TABLA N ${ }^{\circ}$ 13: $\quad$ ANÁLISIS DE COMPONENTES PRINCIPALES PARA VARIABLES DE RELACIONES FAMILIARES

Factor 1

Malas relaciones

en general
Factor 2

Dificultades

económicas y

de comunicación

Falta de comunicación

0,28826

0,31858

Problemas económicos

0,18041

0,24298

Problemas derivados del alcohol y las drogas

0,23257

$-0,46755$

Malas relaciones entre padres e hijos(as)

0,29873

$-0,06313$

Falta de tiempo para compartir en familia

0,1926

0,66425

Malas relaciones entre hermanos

0,2053

$-0,13481$

Maltrato físico y/o psicológico

0,27852

$-0,38895$ 


\section{Construcción de índices sobre nivel de drogadicción comunal}

Para elaborar los índices se consideró a los jóvenes de entre 12 y 29 años inclusive encuestados en la Quinta Encuesta de Drogas en Población General (2006) del Conace. Se construyeron tres índices: dos de intensidad de uso (alcohol, marihuana) y uno de tráfico.

Intensidad de consumo de alcohol: se utiliza la variable de la encuesta que indica cuántos días de los últimos 30 el individuo ha consumido cinco o más vasos o copas de vino, licor o cerveza. Esta cantidad se promedia entre todos los individuos de la comuna (usando el factor de expansión provisto por la encuesta).

Intensidad de consumo de marihuana: se utiliza la variable de la encuesta que indica el número de cigarrillos de marihuana que el individuo consume en un mes. Esta cantidad se promedia entre todos los individuos de la comuna (usando el factor de expansión provisto por la encuesta).

Tráfico: se genera una variable que toma valor uno en caso de que el individuo reporte que en su barrio hay mucho o bastante tráfico de drogas. Esta variable se promedia entre todos los individuos de la comuna (usando el factor de expansión provisto por la encuesta).

\section{BIBLIOGRAFÍA}

Advocates for Youth (2008): Science and Success. Sex Education and Other Programs that Work to Prevent Teen Pregnancy, HIV and Sexually Transmitted Infections. Segunda edición. Washington, DC. Disponible en http://www.advocatesforyouth. org/storage/advfy/documents/sciencesuccess.pdf

- (2009): Adolescent Sexual Health in Europe and the U.S.-Why the Difference?

Aizer, A. \& S. McLanahan (2006): "The Impact of Child Support Enforcement on Fertility, Parental Investment and Child Well Being”. En Journal of Human Resources XLI(1).

Argys, L. y H. E., Peters (2001): "Interactions between Unmarried Fathers and Their Children: The Role of Paternity Establishment and Child-support Policies”. En The American Economic Review, Vol. 91, № 2.

Arkes, J. (2007): “Does the Economy Affect Teenage Substance Abuse?” En Health Econ, 16(1): 19-36.

Arkes, J. \& J. A. Klerman (2009): "Understanding the Link between the Economy and Teenage Sexual Behavior and Fertility”. En J Popul Econ, 22: 517-536.

Becker, Gary S. \& Murphy, Kevin M. (1988): “A Theory of Rational Addiction”. En Journal of Political Economy, University of Chicago Press, vol. 96(4), pp. 675700, agosto. 
Berne, L. \& B. Huberman (1999): European Approaches to Adolescent Sexual Behavior and Responsibility. Advocates for Youth. Washington, DC.

Casey, B., S. Getz \& A. Galvan, A. (2008): “The Adolescent Brain”. En Developmental Review, 28, 62-77.

Darroch, J., S. Singh \& J. Frost, (2001): Differences in Teenage Pregnancy Rates among Five Developed Countries: The Roles of Sexual Activity and Contraceptive Use. Family Planning Perspectives Vol. $33 N^{\circ}$ 6, pp. 244-281.

Donoso, E. (2008): “Embarazo Adolescente: Un Problema País”. En Rev. Chil Obstet Ginecol 2008; 73(5): 291-292.

Dussaillant, F. (2010): “Comportamientos Riesgosos entre los Jóvenes: El Caso de la Actividad Sexual”. Documento de Trabajo No 381, Centro de Estudios Públicos.

Fischhoff, B. (2008): “Assessing Adolescent Decision-making Competence”. En Developmental Review, 28, 12-28.

Gardner, M. \& L. Steinberg (2005): "Peer Influence on Risk Taking, Risk Preference, and Risky Decision Making in Adolescence and Adulthood: An Experimental Study”. En Developmental Psychology, 41, 625-635.

Goldstein, B. y C. Gleizer (2008): "Las preguntas de los y las adolescentes... comenzar por escuchar”. En Morgade y Alonso (eds.), Cuerpos y Sexualidades en la Escuela. De la "Normalidad" a la Disidencia. Paidós.

Instituto Nacional de Estadísticas (2009): "Estadísticas Vitales”. Informe Anual 2006.

Instituto Nacional de la Juventud (INJUV) (2008): Quinta Encuesta Nacional de la Juventud. Disponible en http://www.injuv.gob.cl/pdf/quintaencuestanacionalde juventud.pdf

(2009): Sexta Encuesta Nacional de la Juventud. Principales resultados. Gobierno de Chile.

Jemmott, J., L. Jemmott y G. Fong (2010): "Efficacy of a Theory-Based AbstinenceOnly Intervention Over 24 Months, A Randomized Controlled Trial With Young Adolescents”. Arch Pediatr Adolesc Med. 2010; 164(2): 152-159.

Kirby, D. (2007): "Emerging Answers. Research Findings on Programs to Reduce Teen Pregnancy and Sexually Transmitted Deseases”. The National Campaign to Prevent Teen and Unplanned Pregnancy.

Kruger, D. \& M. Berthelon (2009): "Delaying the Bell: The Effects of Longer School Days on Adolescent Motherhood in Chile”. IZA Discussion Paper 4553.

Levine, P. B. (2001): "The Sexual Activity and Birth Control Use of American Teenagers”. En Gruber, J. (ed.), Risky Behavior Among Youths. An Economic Analysis. The University of Chicago Press.

Linkenbach, J. (2003): "The Montana Model: Development and Overview of a Seven Step Process for Implementing Macro-Level Social Norms Campaigns”. In H. W. Perkins (ed.), The Social Norms Approach to Preventing School and College Age Substance Abuse: A Handbook for Educators, Counselors, and Clinicians. San Francisco: Jossey-Bass.

Linkenbach, J. \& H. W. Perkins, (2003): "Most of Us Are Tobacco Free: An EightMonth Social Norms Campaign Reducing Youth Initiation of Smoking in Montana”. In H. W. Perkins (ed.), The Social Norms Approach to Preventing School and College Age Substance Abuse: A Handbook for Educators, Counselors, and Clinicians. San Francisco: Jossey-Bass. 
Lupica, C. (2009): "Políticas para Promover una Paternidad Comprometida. Los Ejemplos de Suecia y Costa Rica”. En Boletín de la Maternidad, $\mathrm{N}^{\circ}$ 6, Observatorio de la Maternidad.

Maddala, G. S. (1983): "Limited-dependent and Qualitative Variables in Econometrics”. En Econometric Society Monographs. Cambridge University Press.

McLanahan, S. \& M. Carlson (2002): "Welfare Reform, Fertility and Father Involvement”. En JCPR Working Papers, 261, Northwestern University/ University of Chicago Joint Center for Poverty Research.

Miller, Brent C., Brad Benson \& Kevin A. Galbraith (2001): "Family Relationships and Adolescent Pregnancy Risk: A Research Synthesis”. Developmental Review, 21, 1-38.

Neckelmann, M. (2009): “El Efecto Protector de la Religión frente al Consumo de Alcohol y Drogas en Adolescentes Chilenos”. Tesis para optar al grado de magíster en Sociología. Pontificia Universidad Católica de Chile.

Naciones Unidas (2007): "World Fertility Patterns". United Nations - Department of Economic and Social Affairs - Population Division. Disponible en http:// www.un.org/esa/population/publications/worldfertility2007/WorldFertility Patterns\%202007_UpdatedData.xls

Nixon, L. (1997): “The Effect of Child Support Enforcement on Marital Dissolution”. En The Journal of Human Resources 32(1).

Oettinger, G. (1999): "The Effects of Sex Education on Teen Sexual Activity and Teen Pregnancy”. En Journal of Political Economy, 107(3), 606-644.

Pirog, M. \& K. Ziol-Guest (2006): “Child Support Enforcement: Programs and Policies, Impacts and Questions”. En Journal of Policy Analysis and Management 25(4). Wiley.

Plotnik, R., I. Garfinkel, S. McLanahan \& I. Ku (2006): "The Impact of Child Support Enforcement Policy on Nonmarital Childbearing”. En Journal of Policy Analysis and Management, 26(1). Wiley.

Reyna, V. \& F. Farley (2006): "Risk and Rationality in Adolescent Decision-making: Implications for Theory, Practice and Public Policy”. En Psychological Science in the Public Interest, 7, 1-44.

Rivers, S., V. Reyna \& B. Mills (2008): "Risk Taking under the Influence: A Fuzzy-trace Theory of Emotion in Adolescence”. En Developmental Review, 28, 107-144.

Seltzer, J. A., S. S. McLanahan and T. L. Hanson (1998): "Will Child Support Enforcement Increase Father-child Contact and Parental Conflict after Separation?” En I. Garfinkel, S. McLanahan, D. Meyer y J. Seltzer (eds.), Fathers Under Fire: The Revolution in Child Support Enforcement. New York: Russell Sage Foundation.

Solomon-Fears, C. (2002): "Paternity Establishment: Child Support and Beyond". Domestic Social Policy Division. Congressional Research Service. Report RL31467.

Steinberg, L. (2007): "Risk Taking in Adolescence: New Perspectives on Brain and Behavioral Science”. En Current Directions in Psychological Science, 16 (2), 5559.

(2008): “A Social Neuroscience Perspective on Adolescent Risk-taking”. En Developmental Review, 28, 78-106.

Sunstein, C. (2008) “Adolescent Risk-taking and Social Meaning: A Commentary”. En Developmental Review, 28, 145-152. 
Thaler, R. y C. R. Sunstein (2008): Nudge. Improving Decisions about Health, Wealth and Happiness. Yale University Press, New Haven and London.

Van de Ven, Wynand P. M. M. \& Bernard M. S. Van Praag (1981): "The Demand for Deductibles in Private Health Insurance: A Probit Model with Sample Selection”. En Journal of Econometrics, Elsevier, vol. 17(2), 229-252, noviembre.

Weaver, H., G. Smith \& S. Kippax (2005): School-Based Sex Education Policies and Indicators of Sexual Health among Young People: A Comparison of the Netherlands, France, Australia and the United States. Sex Education, Vol. 5, $\mathrm{N}^{\mathrm{o}}$ 2, pp. 171-188. 